DOI: 10.1002/adma.((please add manuscript number))

\title{
Recent Advances in the Development of Semiconducting DPP-Containing Polymers for Transistor Applications
}

By Christian B. Nielsen, * Mathieu Turbiez, and Iain McCulloch

[*] Dr. C. B. Nielsen, Prof. I. McCulloch

Department of Chemistry and Centre for Plastic Electronics

Imperial College London, London SW7 2AZ (United Kingdom)

E-mail: c.nielsen@imperial.ac.uk

Dr. M. Turbiez

Organic Electronic Materials Basel

BASF Schweiz AG, Schwarzwaldallee 215, 4002 Basel (Switzerland)

Keywords: conjugated polymers, donor-acceptor copolymers, field-effect transistors, semiconducting polymers, organic electronics

This progress report summarizes the numerous DPP-containing

polymers recently developed for field-effect transistor applications

including diphenyl-DPP and dithienyl-DPP-based polymers as the

most commonly reported materials, but also difuranyl-DPP,

((Picture for Abstract 40mm broad, $50 \mathrm{~mm}$ high))

diselenophenyl-DPP and dithienothienyl-DPP-containing polymers. We discuss the hole and electron mobilities that were reported in relation to structural properties such as alkyl

substitution patterns, polymer molecular weights and solid state packing, as well as electronic properties including HOMO and LUMO energy levels. We moreover consider important aspects of ambipolar charge transport and highlight fundamental structure-property relations such as the relationships between the thin film morphologies and the charge carrier mobilities observed for DPP-containing polymers.

\section{Introduction}

Since the first polythiophene field-effect transistor (FET) was fabricated in $1986,{ }^{[1]}$ polymeric semiconductors have made considerable progress, now reaching performances similar to amorphous silicon. Unlike their inorganic counterpart, semiconducting polymers have the potential for low cost synthesis and can be processed from solution on roll to roll machinery 
for high throughput, low cost production resulting in light weight, flexible and unbreakable devices. The semiconducting properties are directly related to their molecular ordering, molecular weight, growth mode, and purity. ${ }^{[2]}$ In this context, diketopyrrolopyrrole (DPP) based polymers are currently displaying some of the highest mobilities due to the remarkable aggregating properties of the DPP moities. ${ }^{[3]}$ The potential of DPP containing polymers as semiconductor materials for organic field-effect transistor (OFET) and organic photovoltaic (OPV) application was discovered in 2005 by Mathieu Turbiez. ${ }^{[4]}$ Since the first demonstrations of ambipolar mobilities of $0.1 \mathrm{~cm}^{2} / \mathrm{Vs},{ }^{[5,6]}$ work has escalated on this very promising chemical platform to reach record p-type mobilities of $8.2 \mathrm{~cm}^{2} / \mathrm{Vs}$ and n-type mobilities of $1.56 \mathrm{~cm}^{2} / \mathrm{Vs}{ }^{[7,8]}$ In this progress report, we will summarize the broad scope of publications reporting on various DPP containing polymers and highlight the relationship between the thin film morphology and the mobilities observed.

\section{Diphenyl-DPPs}

The first diphenyl-DPP-based polymers (Figure 1) were reported as early as 1993 by Yu and co-workers for photorefractive applications,${ }^{[9]}$ but very few studies of the semiconducting properties of diphenyl-DPP polymers have since been published (Table 1). The vinylenecopolymer P1 showed a rather low hole mobility mainly ascribed to the formation of an amorphous solid state structure. ${ }^{[10]} \mathbf{P 2}$, on the other hand, with a solubilized phenylenevinylene motif and linear alkyl chains on the DPP unit rather than branched chains as in the case of P1, showed a significantly higher hole mobility of $5.410^{-4} \mathrm{~cm}^{2} / \mathrm{Vs} .^{[11]}$ After annealing at $150^{\circ} \mathrm{C}, \mathrm{X}$-ray diffraction $(\mathrm{XRD})$ of $\mathbf{P 2}$ thin films showed peaks corroborating both lamellar order and $\pi-\pi$ stacking, which correlates well with the large increase in charge carrier mobility when compared to P1. To date, the best OFET properties from a diphenyl-DPPbased copolymer have been reported by Li and co-workers, who copolymerized the diphenylDPP unit with bithiophene to afford P3. ${ }^{[12]}$ Initial SCLC measurements revealed a hole 
mobility of $2.110^{-4} \mathrm{~cm}^{2} / \mathrm{Vs}$ and an electron mobility of $4.710^{-5} \mathrm{~cm}^{2} / \mathrm{Vs}$ and after fabrication of OFET devices, a hole mobility of $0.04 \mathrm{~cm}^{2} / \mathrm{Vs}$ was achieved. Interestingly, only slightly inferior results were obtained with a lower molecular weight batch of P3. Several other thiophene-containing units have also been incorporated into diphenyl-DPP polymers as evident from Table 1 (P4-P6). ${ }^{[13,14]}$ In a comparison of two fused bithiophene systems, namely the cyclopentadithiophene (CPDT, P4) and the dithienopyrrole (DTP, P5), Chen and co-workers found the latter copolymer to perform better in a FET device with a hole mobility of $2.210^{-3} \mathrm{~cm}^{2} / \mathrm{Vs} .^{[14]}$ The lower alkyl density of the DTP-unit as compared to the CPDT-unit with two branched alkyl substituents is most likely responsible for the improved local order (observed as fibrils by atomic force microscopy (AFM) analysis) and hence the larger charge carrier mobility in thin films of $\mathbf{P 5}$.

Whereas numerous diphenyl-DPP-based donor-acceptor type copolymers have been applied with considerable success in organic photovoltaic (OPV) devices, ${ }^{[15]}$ a remarkable lack of similarly high-performing transistor materials is evident from the data presented in Table 1. One explanation for this is illustrated in Figure 2. Steric hindrance between the oxygen atoms of the lactams and the phenyl $\alpha$-hydrogen atoms prevents a coplanar conformation. Quantum-chemical calculations predict a hydrogen-oxygen distance of $2.33 \AA$ (the sum of the Van der Waal radii is $2.61 \AA$ ) and a dihedral angle of $27^{\circ}$ between the phenyl and the DPP-unit as a consequence of this electronic repulsion. There is likely to also be an energetic penalty for planarization of the link between the opposite end of the phenyl group and the comonomer of choice (Ar in Figure 1). These backbone twists are expected to prevent strong intermolecular $\pi-\pi$ interactions and hence a tight and ordered packing, which is often associated with good charge transport properties. The prediction of a low degree of backbone coplanarity and a high probability of disorder on a macroscopic scale for diphenyl-DPP 
copolymers is in good agreement with the observed charge carrier mobilities and the lack of reports on crystallinity for this class of materials.

\section{Dithienyl-DPPs}

As a logical consequence of the anticipated backbone twist when placing phenyl groups adjacent to the DPP-unit, thiophene units have subsequently been introduced instead to afford the dithienyl-DPP motif. As can be seen in Figure 2, the smaller thiophene unit with only one $\alpha$-hydrogen atom can orient in a nearly coplanar fashion with favorable intramolecular sulfur-oxygen interactions (S-O distance of $3.03 \AA$ predicted, sum of Van der Waal radii is $3.32 \AA$ ) and dihedral angles of $12^{\circ}$ between the DPP unit and its adjacent thiophene units. The prospect of dithienyl-DPP copolymers (general structure depicted in Figure 3) in OFET applications is reflected in the large number of polymers of this type included in Table 2.

Zoombelt and co-workers synthesized the homopolymer of a solubilized diphenylDPP unit (P7) and found it to exhibit ambipolar FET properties, although the reported values around $10^{-4} \mathrm{~cm}^{2} / \mathrm{Vs}$ for both the hole and electron mobilities were quite low. ${ }^{[16]}$ More recently, Li and co-workers have also reported on $\mathbf{P 7}$ and found significantly improved charge carrier mobilities on the order of $10^{-2} \mathrm{~cm}^{2} / \mathrm{Vs} .{ }^{[17]}$ Jenekhe's group who reported on P1 also made the corresponding dithienyl-DPP copolymer (P8) and found it to perform much better than $\mathbf{P 1}$, with a hole mobility of $0.17 \mathrm{~cm}^{2} / \mathrm{Vs}$ and an electron mobility of $1.910^{-2}$ $\mathrm{cm}^{2} /$ Vs in a field-effect transistor. ${ }^{[10]}$ XRD confirmed $\mathbf{P 8}$ to be crystalline with a $\pi-\pi$ stacking distance of $3.92 \AA$, which correlates well with the drastic improvement over the amorphous diphenyl-DPP analogue (P1) and the relationship to coplanarity discussed in relation to Figure 2. P9, having a 1,4-phenylene unit rather than the vinylene of $\mathbf{P 8}$, showed similar properties with a good electron mobility of $210^{-2} \mathrm{~cm}^{2} / \mathrm{Vs}$ and a slightly reduced hole mobility of $410^{-2} \mathrm{~cm}^{2} /$ Vs compared to $\mathbf{P 8}{ }^{[18]}$ Another direct comparison of the diphenyl- and dithienyl-DPP systems was provided by Zhang and co-workers, who found P10 to behave 
inferior to the diphenyl-DPP analogue $(\mathbf{P 2}) .{ }^{[11]}$ Both sets of materials appear crystalline and the observed difference in this case more likely stems from the much lower molecular weights obtained for the $\mathbf{P 1 0}$ polymers (Table 2). In 2011, Sonar and co-workers published their work on P11 having a naphthalene unit as the other comonomer and found this polymer to display very good FET properties with maximum hole mobilities approaching $1 \mathrm{~cm}^{2} / \mathrm{Vs} .{ }^{[19}$ ${ }^{20]}$ Instrumental in achieving these results was a thorough optimization process including substrate surface treatments and thermal annealing of the polymer thin film at $140^{\circ} \mathrm{C}$, which by XRD and AFM - was found to significantly improve the crystallinity of the polymer. A series of fluorene analogous structures (fluorene $(\mathbf{P 1 2})$, carbazole $(\mathbf{P 1 3})$, and germafluorene (P14-P15)) have been investigated for copolymerization with the dithienyl-DPP repeat unit. ${ }^{[16,21,22]}$ In FET devices, P12 displays ambipolarity, but both the electron and the hole mobilities are quite poor $\left(10^{-4}-10^{-6} \mathrm{~cm}^{2} / \mathrm{Vs}\right)$. The carbazole- and germafluorene-containing polymers P13 and P14 show much improved hole mobilities on the order of $10^{-2} \mathrm{~cm}^{2} / \mathrm{Vs}$, whereas the germafluorene-based material with longer alkyl chains (P15) is somewhere in between with a hole mobility of $810^{-3} \mathrm{~cm}^{2} / \mathrm{Vs}$. Elongation of the solubilizing alkyl substituents from butyl (P14) to octyl (P15) affects the intermolecular packing drastically, with an increase in the $\pi$ - $\pi$ stacking distance from $3.8 \AA$ to $4.7 \AA$, which in this case is the main factor responsible for the more than 5-fold decrease in charge carrier mobility. ${ }^{\text {[2] }}$

Bearing in mind the excellent charge transport properties and the highly ordered packing of many thiophene-based polymers, ${ }^{[23]}$ the incorporation of thiophene-containing comonomers was an obvious step in the continued development of DPP polymers for highperforming transistor devices. The simplest copolymer, P16, with unsubstituted thiophene has been studied in great detail. ${ }^{[24-26]}$ In 2009, Bijleveld and co-workers reported on P16 with a C6C10 (2-hexyl-1-decyl) branched alkyl chain on the DPP unit and they found a maximum hole mobility of $510^{-2} \mathrm{~cm}^{2} / \mathrm{Vs}$ and an electron mobility of $110^{-2} \mathrm{~cm}^{2} / \mathrm{Vs}$. Interestingly, they 
found a higher molecular weight batch $\left(M_{n} 54 \mathrm{~kg} / \mathrm{mol}\right)$ to give the highest electron mobility, whereas the highest hole mobility was achieved with a lower molecular weight polymer $\left(M_{n}\right.$ $10 \mathrm{~kg} / \mathrm{mol})$. Subsequently, with a slightly longer alkyl chain (C8C12, 2-octyl-1-dodecyl) and a markedly higher molecular weight polymer $\left(\mathrm{M}_{\mathrm{n}} 104 \mathrm{~kg} / \mathrm{mol}\right)$, Zhang and co-workers in 2011 obtained a hole mobility of $0.60 \mathrm{~cm}^{2} / \mathrm{Vs}$ and an electron mobility of $1.210^{-2} \mathrm{~cm}^{2} / \mathrm{Vs}$ for P16. It appears that the slightly longer alkyl chain chosen by Zhang and co-workers yielded a higher molecular weight polymer simply by solubilizing the growing polymer chain more efficiently during the synthesis and thus allowing for a higher degree of polymerization. As firmly established for P3HT, ${ }^{[27]}$ increased molecular weights are often associated with improved charge carrier mobilities and this could very well be the explanation for the improvement in hole mobility observed for P16 by Zhang and co-workers. In 2012, Lee and co-workers improved further on the C8C12-functionalised P16 by achieving a hole mobility of $1.57 \mathrm{~cm}^{2} / \mathrm{Vs}$ and an electron mobility of $0.18 \mathrm{~cm}^{2} / \mathrm{Vs}$ upon thermal annealing at $150^{\circ} \mathrm{C}$. Introducing bithiophene as the other comonomer instead of thiophene effectively changes the separating unit between DPP units from a terthiophene to a quaterthiophene moiety. P17, with an unsubstituted bithiophene unit, was reported by Zhang and co-workers to have a maximum FET hole mobility of $0.74 \mathrm{~cm}^{2} / \mathrm{Vs}^{[25]}$ Using the same solubilising group (C8C12) and obtaining a similar molecular weight with a $\mathrm{M}_{\mathrm{n}}$ of approximately $60 \mathrm{~kg} / \mathrm{mol}$ (Table 2), Ha and co-workers used their batch of P17 to fabricate a field-effect transistor displaying a maximum hole mobility as high as $1.04 \mathrm{~cm}^{2} / \mathrm{Vs} .{ }^{[28]}$ Around the same time, $\mathbf{P 1 7}$ afforded a hole mobility of $0.97 \mathrm{~cm}^{2} / \mathrm{Vs}$ in the hands of Li and co-workers. ${ }^{[29]}$ Both Ha's and Zhang's results were obtained after thermal annealing at $150^{\circ} \mathrm{C}$, while $\mathrm{Li}$ and co-workers achieved their highest mobility with a more moderate $100^{\circ} \mathrm{C}$ annealing step. $\mathrm{Li}$ and co-workers furthermore reported on a significant drop in FET performance (to $0.39 \mathrm{~cm}^{2} / \mathrm{Vs}$ ) for a lower molecular weight batch of $\mathbf{P 1 7}\left(\mathrm{M}_{\mathrm{n}} 21 \mathrm{~kg} / \mathrm{mol}\right.$ vs. $25 \mathrm{~kg} / \mathrm{mol}$, Table 2), although the measured 
difference in molecular weight is minimal. ${ }^{[29]}$ In this context, it is important to stress that DPP-containing polymers are known to aggregate, especially in concentrated solutions needed for GPC measurements, and it is therefore difficult to extract accurate molecular weight information even from high-temperature GPC set-ups and even more difficult to compare molecular weight information obtained in different research groups. Both P16 and P17 were found to be rather crystalline and increased ordering was observed upon thermal annealing as expected; $\pi-\pi$ stacking distances were found to be $3.65-3.8 \AA$ and this tight interchain packing is in good agreement with the high charge carrier mobilities measured for both polymers. Other thiophene-based transistor materials with unsubstituted oligothiophene repeat segments (terthiophene for $\mathbf{P 1 6}$ and quaterthiophene for P17) have often been further modified by attaching linear alkyl chains onto the rather flexible and disordered oligothiophene segment; a strategy which has repeatedly improved the structural order in the solid state and hence the FET performance. ${ }^{[30]}$ P18 represents this approach and so do P19 and P20 to some extent, although the branched solubilising groups in these two latter cases are more disordered. ${ }^{[6,31,32]}$ The best mobilities were found for P18, which showed balanced hole and electron mobilities around $0.1 \mathrm{~cm}^{2} / \mathrm{Vs}$, and P19, which had a similar hole mobility (Table 2), while the hole mobility of $\mathbf{P 2 0}$ was approximately two orders of magnitude lower. These results are all inferior to those reported for P16 and P17 and it appears that DPPcontaining donor-acceptor type copolymers have less need for further polymer backbone rigidification than more flexible thiophene-based polymers such as P3HT and PBTTT instead a lower alkyl chain density seems preferable for optimum packing and charge transport.

Turning the attention to the next chalcogen atom after sulfur, selenophene is often found to stabilize a polymer LUMO and thus introduce more quinoid character and effectively narrow the band gap when compared to thiophene in donor-acceptor type 
copolymers. ${ }^{[33]}$ Additionally, the large selenium atom presents a large frontier orbital contribution, helpful for intermolecular charge transport. Lin and co-workers found this to have a beneficial effect: polymer P21 containing selenophene instead of thiophene (P16) showed a maximum hole mobility of $1.62 \mathrm{~cm}^{2} / \mathrm{Vs}$ and an electron mobility of $0.14 \mathrm{~cm}^{2} / \mathrm{Vs}$ when processed from a high-boiling solvent and subjected to thermal annealing. ${ }^{[34]}$ XRD analysis confirmed an increase in structural order when $\mathbf{P 2 1}$ was processed from higher boiling solvents and also when subject to thermal annealing and AFM analyses indicated formation of dense and highly interconnected domains, which could explain the remarkable charge carrier properties of this high molecular weight polymer. In their study of P17, Ha and co-workers also included the biselenophene derivative, P22, which was found to perform significantly better than the sulfur analogue with a hole mobility of $1.5 \mathrm{~cm}^{2} / \mathrm{Vs}^{[28]} \mathrm{X}$-ray studies indicated that $\mathbf{P 2 2}$ was slightly more crystalline than P17; despite having identical solubilising alkyl chains (C8C12) on the DPP moiety, P22 was moreover found to pack with slightly shorter lamellae spacing than P17 (18.5 ̊ vs. $18.9 \AA$ A). With polymer P23, Lee and co-workers saw the triple substitution of sulfur with selenium to cause an increase in hole mobility from $110^{-3} \mathrm{~cm}^{2} / \mathrm{Vs}(\mathbf{P 2 0})$ to $210^{-3} \mathrm{~cm}^{2} / \mathrm{Vs}^{[32]}$

Other comonomers with structural similarities of the bithiophene unit have also been used; P24 with an unsubstituted phenylene unit inserted between two alkylated thiophenes gave a good hole mobility of $0.27 \mathrm{~cm}^{2} /$ Vs in a FET device. ${ }^{[35]}$ In 2012 , Chen and co-workers copolymerized the dithienyl-DPP monomer with the (E)-2-(2-(thiophen-2-yl)vinyl)thiophene unit to afford P25, which proved very successful for FET applications. ${ }^{[7]}$ With C8C12 solubilising groups on the DPP moiety, an impressive maximum hole mobility of $4.5 \mathrm{~cm}^{2} / \mathrm{Vs}$ was achieved, while the C10C14 (2-decyl-1-tetradecyl) derivative afforded an unprecedented hole mobility of $8.2 \mathrm{~cm}^{2} / \mathrm{Vs}$ after thermal annealing at $180^{\circ} \mathrm{C}$. High molecular weights and narrow polydispersities of the two $\mathbf{P 2 5}$ polymers along with a high degree of crystallinity in 
the solid state with close $\pi-\pi$ contacts (3.66 - 3.72 $\AA$ ) are some of the prerequisites for $\mathbf{P} 25$ to perform well in transistors. Additionally, AFM micrographs indicate, especially for the bestperforming C10C14 derivative, large interconnected fibrillar networks, which are crucial for long-range charge transport. Chen and co-workers furthermore highlighted a good environmental and operational stability of $\mathbf{P 2 5}$ with negligible loss in device performance upon repeated testing and a high tolerance to repeated testing in humid air manifested by a hole mobility above $5 \mathrm{~cm}^{2} / \mathrm{Vs}$ for the $\mathrm{C} 10 \mathrm{C} 14$-solubilised version of $\mathbf{P 2 5}$. The comonomer used for the synthesis of $\mathbf{P 2 6}$ contained four thiophenes and a central vinylene group to afford a repeat unit with six thiophenes and one vinylene group for every DPP unit. ${ }^{[36]}$ The increased thiophene-content resulted in a reduced hole mobility of $510^{-2} \mathrm{~cm}^{2} / \mathrm{Vs}$. Rather than pursuing a more flexible and soluble copolymer system as above, $\mathbf{P 2 7}$ and the application of thieno[3,2-b]thiophene (TT) as a comonomer presents a less soluble, fused aromatic systems and their strong tendencies to planarize the conjugated system and $\pi$-stack with neighboring polymer chains. Bijleveld and co-workers used $\mathrm{C} 6 \mathrm{C} 10$ as the solubilizing alkyl group and they obtained moderate mobilities $\left(\mu_{\mathrm{h}}=310^{-2} \mathrm{~cm}^{2} / \mathrm{Vs}\right.$ and $\left.\mu_{\mathrm{e}}=910^{-3} \mathrm{~cm}^{2} / \mathrm{Vs}\right)$ with a fairly low molecular weight polymer (P27, Table 2). ${ }^{[37]}$ With the C8C12 alkyl group and a slightly higher molecular weight, Zhang and colleagues measured a more than 10-fold higher electron mobility of $0.38 \mathrm{~cm}^{2} /$ Vs for their sample of P27. ${ }^{[25]}$ In 2010 , Li and co-workers reported a hole mobility of $0.94 \mathrm{~cm}^{2} / \mathrm{Vs}$ and very recently, the Sirringhaus group published very impressive ambipolar FET results displaying both electron and hole mobilities above 1 $\mathrm{cm}^{2} / \mathrm{Vs}\left(\mu_{\mathrm{h}}=1.36 \mathrm{~cm}^{2} / \mathrm{Vs}\right.$ and $\left.\mu_{\mathrm{e}}=1.56 \mathrm{~cm}^{2} / \mathrm{Vs}\right) .{ }^{[8,38]}$ These two last sets of results were both obtained with the $\mathrm{C} 8 \mathrm{C} 12$ substitution pattern and a much higher molecular weight polymer, provided by the McCulloch group at Imperial College, although - as mentioned earlier comparison of molecular weights is not straightforward for highly aggregating DPP polymers. Another highly significant difference between the four studies of P27 presented 
here is the choice of processing conditions and in particular the thermal annealing step. In the work of Bijleveld, $\mathbf{P 2 7}$ was annealed at $100^{\circ} \mathrm{C}$, while Zhang and colleagues annealed their device at $150^{\circ} \mathrm{C}$. These experimental details in conjunction with the improved mobilities obtained by $\mathrm{Li}\left(200^{\circ} \mathrm{C}\right.$ annealing) and Sirringhaus $\left(320^{\circ} \mathrm{C}\right.$ annealing) clearly indicate a correlation between annealing temperature and FET device performance. Particularly for high electron mobilities to be observed, a very harsh annealing step seems to be required. The high-temperature annealing process is speculated to not only improve the polymer crystallinity but also possibly reduce the concentration of charge traps and the polymer/electrode contact resistance. ${ }^{[8]}$ In the latest report on P27, Lee and co-workers fabricated impressive FET devices of both the C6C10-derivative $\left(\mu_{\mathrm{h}}=0.79 \mathrm{~cm}^{2} / \mathrm{Vs}\right.$ and $\mu_{\mathrm{e}}=$ $\left.0.04 \mathrm{~cm}^{2} / \mathrm{Vs}\right)$ and the C8C12-derivative $\left(\mu_{\mathrm{h}}=1.93 \mathrm{~cm}^{2} / \mathrm{Vs}\right.$ and $\left.\mu_{\mathrm{e}}=0.06 \mathrm{~cm}^{2} / \mathrm{Vs}\right)$ with maximum hole mobilities reaching $2.2 \mathrm{~cm}^{2} / \mathrm{Vs}$ after thermal treatment at $150^{\circ} \mathrm{C}^{[26]} \mathrm{X}$-Ray studies revealed as expected a high degree of crystallinity and a tight intermolecular packing with $\pi-\pi$ stacking distances of 3.71 - $3.8 \AA$ for P27. In this regard, P27 shows close similarities to the thiophene (P16) and the bithiophene (17) analogues, which also displayed high mobilities and highly ordered solid state structures with strong $\pi-\pi$ interactions. Nevertheless, some interesting differences also appear when examining the structural ordering in greater detail; those aspects will be discussed more thoroughly towards the end of this manuscript.

Various alkyl-substituted thienothiophenes and their derivatives have also been tested (P28-P30, Table 2) and just as in the comparison between bithiophene and alkylated bithiophenes, the higher alkyl density was not found to be beneficial for the FET properties. ${ }^{[37,39]}$ The best hole mobility of $110^{-2} \mathrm{~cm}^{2} /$ Vs was reported for $\mathbf{P 2 9}$, which also showed ambipolar properties with an electron mobility of $210^{-3} \mathrm{~cm}^{2} / \mathrm{Vs} .^{[37]}$ The analogue with linear alkyl chains (P28) had an inferior performance as did an extended derivative with 
two extra thiophene units (P30). In the case of $\mathbf{P 2 8}$, the poorer performance is most likely related to a low degree of polymerization.

Benzodithiophenes (BDTs) have been used very successfully in donor-acceptor type polymers for organic photovoltaic applications, ${ }^{[15]}$ and many BDT-containing DPP polymers have been investigated for their FET properties as well. ${ }^{[40]}$ Polymers P31 through P36 represent work on the benzo[1,2-b:4,5-b']dithiophene isomer. Li and colleagues compared different substitution patterns by varying both the solubilising group on the dithienyl-DPP unit as well as the alkyl substituents on the BDT unit. ${ }^{[41]}$ Attaching branched alkyl groups onto both the DPP and the BDT unit (P32) afforded the material with the lowest degree of crystallinity and not surprisingly the lowest charge carrier mobility. Substituting one of the branched alkyl groups with a linear alkyl chain had a beneficial effect both when the modification was done at the BDT (P31) and the DPP unit (P33). Both materials were more crystalline than P32 and showed improved FET characteristics with a maximum hole mobility of $1.610^{-3} \mathrm{~cm}^{2} / \mathrm{Vs}$ observed for $\mathbf{P 3 3}$, which was the best performing material of the three. P33, with a linear alkyl chain on the DPP unit, displayed closer $\pi-\pi$ distances $(3.97 \AA)$ than P31, which had the linear alkyl chain on the BDT unit (4.09 $\AA$ ). Polymers P34, P35 and P36 were only probed by zero-field transistor measurements as the main focus of these studies was on OPV applications. ${ }^{[13,42]}$ P35 and P36 with linear alkoxy-groups showed similar, low hole mobilities similar to the diphenyl-DPP analogue (P6), whereas the charge carrier properties of P34 was approximately one order of magnitude better; an observation mainly attributed to a significantly higher molecular weight. Benzo[2,1-b;3,4-b']dithiophene is another BDT isomer used in polymers P37 and P38 (Table 2). Yuan and co-workers found a rather low hole mobility on the order of $10^{-5} \mathrm{~cm}^{2} / \mathrm{Vs}$ for $\mathbf{P 3 7}$ with branched alkyl chains on the BDT unit and long linear alkyl chains on the DPP unit, while Zhang and colleagues measured a zero-field mobility of $1.710^{-3} \mathrm{~cm}^{2} / \mathrm{Vs}$ for $\mathbf{P 3 8}$ having linear alkoxy groups on the 
BDT unit and branched 2-ethyl-1-hexyl groups on the DPP moiety. ${ }^{[43,44]}$ A simple comparison of the two BDT isomers reveals that typically the benzo[1,2-b:4,5-b']dithiophene isomer performs better with most comomoners, and also with the dithienyl-DPP unit. However, the mobility of $\mathbf{P 3 8}$ surpasses the mobility of $\mathbf{P 3 6}$, thus favoring the benzo[2,1b;3,4-b']dithiophene isomer in this case.Fused aromatic systems related to the BDT moiety that have been incorporated into dithienyl-DPP copolymers include cyclopentadithiophene (CPDT, P39), dithienopyrrole (DTP, P40-P41) and dithienothiophene (DTT, P42-P45) as illustrated by their structures in Table 2. For P39, which has a rather low hole mobility of 2.1 $10^{-3} \mathrm{~cm}^{2} / \mathrm{Vs}$, the CPDT unit is solubilized by grafting two alkyl chains onto the carbon atom that bridges the two thiophene units. ${ }^{[16]}$ Due to the $\mathrm{sp}^{3}$-hybridization of the central carbon bridge, the alkyl chains protrude out of the plane of the polymer backbone. This tetrahedral bonding geometry can potentially prevent advantageous $\pi-\pi$ interactions and the DTP polymers $\mathbf{P 4 0}$ and $\mathbf{P 4 1}$ with $\mathrm{sp}^{2}$-hybridized bridging atoms can thus be seen as variants designed for more efficient intermolecular $\pi$-stacking. Both $\mathbf{P 4 0}$ from McCullough's group and P41 from Zhou and co-workers did indeed show very tight $\pi$-stacking behavior with repeat distances of $3.7 \AA$ and $3.64 \AA$, respectively, which corroborates well with high FET electron mobilities of $0.41 \mathrm{~cm}^{2} / \mathrm{Vs}$ and $0.05 \mathrm{~cm}^{2} / \mathrm{Vs}$, respectively. ${ }^{[45,46]}$ Very recently, Jung and co-workers reported a maximum hole mobility of $0.75 \mathrm{~cm}^{2} / \mathrm{Vs}$ for $\mathbf{P 4 2}$ using an unsubstituted DTT comonomer and a C8C12-substituted dithienyl-DPP unit. ${ }^{[47]}$ Considering the structural similarity of the DTT unit with the high-performing TT (P27) and DTP (P40) units, this significant result is not entirely unexpected. Previous studies on DTT-containing materials described much poorer transistor performances and properties seemed limited by very low molecular weights (P43 and P44) and potentially some degree of backbone twisting due to solubilising alkyl chains on the $\beta$-positions of the DTT unit. ${ }^{[48]}$ Prior to the reporting of $\mathbf{P 4 2}$, the best FET performance for a DTT-containing polymer was found for $\mathbf{P 4 5}$, which had 
a high molecular weight similar to that of $\mathbf{P 4 2}$ and a hole mobility of $3.310^{-2} \mathrm{~cm}^{2} / \mathrm{Vs} .^{[49]}$ Further extension of the fused aromatic system has been explored to some extent as well. Both Wang and co-workers and Sun and co-workers investigated the potential of the indacenodithiophene (IDT, P46-P47) unit, which contains five fused aromatic units and has two $\mathrm{sp}^{3}$-hybridized carbon bridges of the type discussed for CPDT. ${ }^{[50,51]} \mathbf{P 4 6}$, with four dodecyl groups attached to the two carbon bridges, showed an approximately four times higher hole mobility $\left(6.510^{-2} \mathrm{~cm}^{2} / \mathrm{Vs}\right)$ than $\mathbf{P 4 7}$, indicating that the four bulky $p$-hexylphenyl substituents of $\mathbf{P 4 7}$ are somewhat disadvantageous to tight molecular ordering and efficient intermolecular charge transport. Ashraf and colleagues argued that the longer silicon-carbon bond could be beneficial in the molecular design of efficient transistor materials and did indeed find a hole mobility of $0.65 \mathrm{~cm}^{2} / \mathrm{Vs}$ for the Si-IDT derivate $(\mathbf{P 4 8})$, which is one order of magnitude larger than what was reported for the IDT derivative with slightly longer alkyl chains (P46). ${ }^{[52]}$ Wudl's group recently reported on $\mathbf{P 4 9}$ containing emeraldicene, which can be seen as an extended IDT derivative. ${ }^{[53]}$ Here, the bridging carbon atoms are part of the anthracene motif and are thus unable to accommodate solubilising substituents. Instead, alkyl groups were attached to the free $\beta$-positions of the thiophenes, which could inflict some backbone twisting, but excellent mobilities were nevertheless achieved $\left(\mu_{\mathrm{h}}=0.29 \mathrm{~cm}^{2} / \mathrm{Vs}\right.$ and $\mu_{\mathrm{e}}=0.25 \mathrm{~cm}^{2} / \mathrm{Vs}$ ) after high temperature annealing. In agreement with the good ambipolar properties, XRD analysis revealed a high degree of structural order and a tight $\pi$ - $\pi$ stacking (4.03 Å) after thermal annealing. P50 and P51 represent two other anthracene-containing comonomers published by Lee and co-workers. ${ }^{[54]}$ P51, with backbone $\pi$-delocalization facilitated through the 9,10-positions of the anthracene moiety, displayed a nearly five-fold larger hole mobility $\left(0.12 \mathrm{~cm}^{2} / \mathrm{Vs}\right.$, Table 2$)$ than the corresponding 2,6-conjugated anthracene derivative (P52). The authors ascribe the superior performance of P52 compared to P51 to a 
lower band gap resulting from stronger intramolecular donor-acceptor interactions and a smoother surface morphology.

P52 contains a triphenylamine unit that on one hand is well-known as an efficient hole transporting material, but on the other hand is expected to disrupt structural ordering. Lee and co-workers found those opposing factors to result in $\mathbf{P 5 2}$ being an amorphous material yet having a moderate and highly reproducible FET hole mobility of $3.310^{-3}$ $\mathrm{cm}^{2} / \mathrm{Vs}^{[55]}$

The strong electron-accepting unit 2,1,3-benzothiadiazole (BT, P53) has previously been used successfully as a constituent in high-performing semiconducting materials, ${ }^{[56]}$ and it has recently attracted significant attention in dithienyl-DPP polymers as well. Sonar and coworkers were the first to report on the FET properties of P53 and found both a high hole mobility of $0.35 \mathrm{~cm}^{2} / \mathrm{Vs}$ and a equally high electron mobility of $0.40 \mathrm{~cm}^{2} / \mathrm{Vs}$ for a moderate molecular weight sample $\left(\mathrm{M}_{\mathrm{n}} 42 \mathrm{~kg} / \mathrm{mol}\right)$ after annealing the sample at $200^{\circ} \mathrm{C}^{[57]} \mathrm{XRD}$ analysis revealed a crystalline material with a short $\pi$ - $\pi$ stacking distance of $3.73 \AA$ while AFM analysis indicated the formation of interconnected networks upon annealing. Cho and colleagues later reported on a higher molecular weight sample of $\mathbf{P 5 3}\left(\mathrm{M}_{\mathrm{n}} 136 \mathrm{~kg} / \mathrm{mol}\right)$, which in their laboratories gave somewhat lower charge carrier mobilities $\left(\mu_{\mathrm{h}}=0.1 \mathrm{~cm}^{2} / \mathrm{Vs}\right.$ and $\mu_{\mathrm{e}}=0.09 \mathrm{~cm}^{2} / \mathrm{Vs}$ ) although it is worth noting that they only annealed their device at $80^{\circ} \mathrm{C}$ and found the material to be amorphous. ${ }^{[58]}$ Most recently, Sirringhaus' group published a hole mobility of $0.33 \mathrm{~cm}^{2} / \mathrm{Vs}$ and a higher electron mobility of $0.57 \mathrm{~cm}^{2} / \mathrm{Vs}$ for P53. ${ }^{[59]}$ In agreement with the work of Sonar, they found P53 to be crystalline in the solid state with a $\pi$ $\pi$ stacking distance of $3.65 \AA$. In addition to differences in molecular weight affecting the observed differences in FET device performance for P53 (Table 2), the studies by Sonar and co-workers on different annealing conditions appear to be highly relevant for this material. While the pristine sample afforded hole and electron mobilities of $0.03-0.06 \mathrm{~cm}^{2} / \mathrm{Vs}$, 
annealing at $80^{\circ} \mathrm{C}$ improved the values to roughly $0.2 \mathrm{~cm}^{2} / \mathrm{Vs}$. Higher annealing temperature of $120^{\circ} \mathrm{C}$ and $180^{\circ} \mathrm{C}$ improved the electron mobility without significantly affecting the hole mobility, whereas annealing at $200^{\circ} \mathrm{C}$ ultimately gave the highest hole and electron mobilities of around $0.4 \mathrm{~cm}^{2} / \mathrm{Vs}$. This corresponds well with the fact that Sirringhaus and co-workers also achieved their best mobilities after a $200^{\circ} \mathrm{C}$ annealing step. Sonar and colleagues have recently followed up on their initial work on P53 and have obtained values above 0.50 $\mathrm{cm}^{2} / \mathrm{Vs}$ for both hole and electron transport (Table 2) after optimization of surface treatment conditions and FET device configurations. ${ }^{[60]}$ In an attempt to further increase the electronaccepting properties of the comonomer, Lee and colleagues introduced the bis-BT unit (P54) and found it to be predominantly an n-type semiconductor with an electron mobility twice as high as the hole mobility $\left(\mu_{\mathrm{h}}=6.510^{-4} \mathrm{~cm}^{2} / \mathrm{Vs}\right.$ and $\left.\mu_{\mathrm{e}}=1.310^{-3} \mathrm{~cm}^{2} / \mathrm{Vs}\right){ }^{[61]}$ The moderate charge carrier mobilities of P54 are most likely a consequence of the backbone twist caused by the biphenyl-linkage of the bis-BT unit (the two BT units are twisted approximately $60^{\circ}$ away from coplanarity), which is also reflected in the absence of diffraction peaks when the material is subjected to XRD analysis. Interestingly, Lee and co-workers have compared polymers P52, P53 and P54 and highlight the significant change in FET properties when going from the electron rich triphenylamine comonomer and the resulting polymer, P52, which serves as a good p-type transistor material, to the electron poor BT unit affording an ambipolar semiconductor (P53) and finally to the even more electron poor bis-BT unit, which gives rise to a n-type transistor material $(\mathbf{P 5 4}) .{ }^{[61]}$ A very similar approach was taken by Wudl's group when they reported on the previously discussed polymer P24; in addition to studying the comonomer with a central phenylene unit (P24), they also synthesized the electron poor BT analogue (P55) and two even more electron poor benzobisthiadiazole (BBT) derivatives (P56 and P57) ${ }^{[35]}$ P55 appeared more crystalline than P24, but the FET properties were similar given that a maximum hole mobility of $0.23 \mathrm{~cm}^{2} / \mathrm{Vs}$ was measured 
for P55. Both materials showed optimum performance after $160-200^{\circ} \mathrm{C}$ annealing, while especially P55 suffered a drastic decrease in FET performance upon higher temperature annealing. The BBT-containing polymers (P56 and P57) - in similarity to the most electron poor member (P54) of the series studied by Lee and co-workers - turned out to be most effective as electron-transporting materials, although in this case, the hole transport properties were almost equally impressive. $\mathbf{P 5 6}$ displayed a maximum hole mobility of $0.83 \mathrm{~cm}^{2} / \mathrm{Vs}$ and a very high maximum electron mobility of $1.36 \mathrm{~cm}^{2} / \mathrm{Vs}$ after $200^{\circ} \mathrm{C}$ annealing. P57, with longer alkyl chains on the thiophene units, showed similar n-type characteristics $\left(\mu_{\mathrm{e}}=1.32\right.$ $\mathrm{cm}^{2} / \mathrm{Vs}$ ) and a somewhat higher hole mobility of $1.17 \mathrm{~cm}^{2} / \mathrm{Vs}$ after annealing at $240^{\circ} \mathrm{C} . \mathrm{X}$ Ray analyses indicated that P57 was actually less crystalline than P55 and the authors hypothesize that stronger interchain interactions caused by a high degree of backbone coplanarity are at least partly accountable for the superior ambipolar FET performance observed for P56 and P57 relative to P24 and P55. In 2012, Hong and co-workers used a polycondensation reaction to introduce the azine-moiety (P58) as a new electron-poor constituent in DPP-containing polymers. ${ }^{[62]}$ This material also showed promising ambipolar charge transport properties with a maximum hole mobility of $0.36 \mathrm{~cm}^{2} / \mathrm{Vs}$ and electron mobility of $0.41 \mathrm{~cm}^{2} / \mathrm{Vs}$. Again, the best performance is achieved after $200^{\circ} \mathrm{C}$ annealing and this is firmly supported by XRD and AFM analyses, which show increased crystallinity and larger interconnected domains.

\section{Diaryl-DPPs}

In addition to the numerous variations of the comonomer unit as described earlier, skilled synthetic chemists quickly sought out the possibility of also modifying the thienyl-linkage to the DPP unit. As illustrated in Figure 4, this opens up the avenue of independently varying both $\mathrm{Ar}_{1}$ and $\mathrm{Ar}_{2}$ in an effort to further optimize the electrical properties of DPP-containing copolymers as well as to further understand the structure-property relations. 
With the many high-performing dithienyl-DPP materials in mind, the initial focus of attention was primarily the furan and selenophene analogues. As illustrated in Figure 5, in contrast to the thienyl analogue, both the difuranyl-DPP and the diselenophenyl-DPP derivative can, according to density functional theory calculations with Gaussian, adopt completely coplanar conformations in their energy-minimized states. In comparison with the dithienyl-DPP, the smaller oxygen atom of furan and the shorter $\mathrm{C}-\mathrm{O}$ bond (relative to the $\mathrm{C}$ $\mathrm{S}$ bond) result in less steric hindrance between the DPP unit and the neighboring aryl group (intramolecular O-O distance of $2.98 \AA$, the sum of the Van der Waal radii is $3.04 \AA$, Figure 5a) and therefore allow for a more coplanar structure. Diselenophenyl-DPP, on the other hand, contains the much larger selenium atom (Figure 5b). Intuitively, this would mean increased steric hindrance, but according to the theoretical calculations a completely coplanar conformation is preferred with an intramolecular Se-O distance of $2.94 \AA$, which is much smaller than the sum of the Van der Waal radii of $3.42 \AA$. This is indicative of an attractive Se-O interaction as also seen for S-O in the case of dithienyl-DPP; the coplanar conformation can moreover be accommodated by the higher polarizability of the selenophene unit, which is also seen by a slight distortion of the selenophene geometry.

Very recently, Sonar and colleagues investigated three difuranyl-DPP materials containing benzene (P59, Table 3), naphthalene (P60) and anthracene (P61), respectively, as the other comonomer. ${ }^{[63]}$ In FET devices, hole mobilities of $0.04-0.11 \mathrm{~cm}^{2} /$ Vs were measured for the three polymers with the highest value observed for P60, which also showed the shortest $\pi-\pi$ stacking distance as well as the shortest lamellar spacing in the solid state. The better performance of $\mathbf{P 6 0}$ corroborates well with the higher mobility of P11 as compared to P9, although it is clear that the difuranyl-DPP unit in this case is less efficient for charge transport than the dithienyl-DPP moiety. Bijleveld and co-workers also studied P59; they found a rather low hole mobility of $310^{-3} \mathrm{~cm}^{2} / \mathrm{Vs}$ in addition to a slightly higher 
electron mobility of $710^{-3} \mathrm{~cm}^{2} / \mathrm{Vs}^{\left[{ }^{[64]}\right.}$ Bijleveld's study also encompassed the furan (P62) and the thiophene (P63) copolymer, which both showed similar FET properties with hole mobilities in the $10^{-3} \mathrm{~cm}^{2} /$ Vs range, whereas P59 and P63 showed significantly better electron transporting properties than $\mathbf{P 6 2}\left(10^{-3} \mathrm{~cm}^{2} / \mathrm{Vs}\right.$ and $10^{-5} \mathrm{~cm}^{2} / \mathrm{Vs}$ respectively, Table 3). Fréchet's group investigated the role of the DPP side chain for P63 and found linear alkyl chains (C12, C14 and C16) to promote a higher degree of crystallinity and closer $\pi-\pi$ interactions, although this had limited effect on the zero-field mobilities since the branched analogue (C2C6) performed as well or better than the linear alkyl chain derivatives. ${ }^{[65]} \mathbf{P 6 4}$, which was reported by Li and co-workers in 2011, represents the best difuranyl-DPP transistor material developed to date with a maximum hole mobility of $1.54 \mathrm{~cm}^{2} / \mathrm{Vs}{ }^{[66]}$ As with most other high-performing DPP-based semiconducting polymers discussed so far, a strong correlation between the FET properties and the annealing temperature was observed. The as-cast film of $\mathbf{P 6 4}$ showed a moderate hole mobility of $0.13 \mathrm{~cm}^{2} / \mathrm{Vs}$, while values of $0.51 \mathrm{~cm}^{2} / \mathrm{Vs}$ and $0.65 \mathrm{~cm}^{2} / \mathrm{Vs}$, respectively, were achieved with $100^{\circ} \mathrm{C}$ and $150^{\circ} \mathrm{C}$ annealing before reaching a maximum value of $1.54 \mathrm{~cm}^{2} / \mathrm{Vs}$ after thermal annealing at $200^{\circ} \mathrm{C}$. To the best of our knowledge, this is the only example so far in the literature of a difuranyl-DPP copolymer outperforming the corresponding dithienyl-DPP material (P17), although it must be emphasized that no direct comparison between P17 and P64 has been conducted. It is moreover noteworthy that P64, despite the improved charge carrier properties, appears less crystalline than P17 and clearly organizes in the solid state with a much longer $\pi-\pi$ stacking distance (4.4 $⿱$ ). P65, the furan-analogue of the high-performing $\mathbf{P 2 5}$ polymer, is another example where the introduction of furan causes an apparent loss of structural order and a significant drop in FET device performance. ${ }^{[67]}$ Optimization of processing conditions including choice of solvent and annealing temperature afforded a hole mobility of 0.13 $\mathrm{cm}^{2} /$ Vs for P65; a modest value when directly compared to the C8C12-functionalised P25 ( $\mu_{\mathrm{h}}$ 
$\left.=4.5 \mathrm{~cm}^{2} / \mathrm{Vs}\right)$. Predictably, the BT-containing difuranyl-DPP copolymer (P66) reported by Sonar and co-workers shows good ambipolar FET properties with a particularly good electron mobility of $0.56 \mathrm{~cm}^{2} /$ Vs (Table 3). ${ }^{[68]}$ In that respect, $\mathbf{P 6 6}$ bears a strong resemblance to its thiophene-analogue (P53) although the hole mobility is somewhat reduced for $\mathbf{P 6 6}$ $\left(0.20 \mathrm{~cm}^{2} / \mathrm{Vs}\right.$ versus $0.33-0.53 \mathrm{~cm}^{2} / \mathrm{Vs}$ for P53). Once again, the $\mathrm{n}$-type charge carrier properties proved much more sensitive to the thermal annealing conditions than the p-type transport. The electron mobility was increased more than three-fold when annealed at $200^{\circ} \mathrm{C}$, whereas the hole mobility remained more or less constant over the investigated range of annealing temperatures $\left(120-200^{\circ} \mathrm{C}\right)$.

Heeney's group successfully synthesized the diselenophenyl-DPP monomer and has reported on three diselenophenyl-DPP-containing polymers, namely P67, P68 and P69 as illustrated in Table 3. ${ }^{[59,69]} \mathbf{P 6 7}$, the all-selenium analogue of P16, displays balanced ambipolar transport properties with both hole and electron mobilities reaching $0.1 \mathrm{~cm}^{2} / \mathrm{Vs}$ after thermal annealing at $200^{\circ} \mathrm{C}$. Compared to the best results reported for P16 (Table 2), the hole mobility of P67 is significantly lower, while the electron mobilities of P16 and P67 are comparable. The selenium atoms are thought to stabilize and delocalize the LUMO to a larger extent than sulfur in these structures and this should be beneficial for the electron transport, which was also seen with $\mathbf{P 2 1}\left(\mu_{\mathrm{e}}=0.14 \mathrm{~cm}^{2} / \mathrm{Vs}\right)$, even though no further improvement of the electron transport was seen when going from P21 to P67. Introduction of the thienothiophene (TT) unit was previously shown to be advantageous to the charge transport (P16 versus P27) and Heeney's group found this to be true for the diselenophenyl-DPP system as well. After $250^{\circ} \mathrm{C}$ annealing, $\mathbf{P 6 8}$ displayed a much higher hole mobility of $1.1 \mathrm{~cm}^{2} / \mathrm{Vs}$ and also an improved electron mobility of $0.15 \mathrm{~cm}^{2} /$ Vs when compared to P67. ${ }^{[69]}$ For P68, the comparison with the sulfur-analogue (P27, Table 2) indicates that the incorporation of selenium in this case reduced both the electron and the hole mobility. It must again be noted 
that this judgment is based on just one study of $\mathbf{P 6 8}$ compared to several independent investigations of $\mathbf{P 2 7}$, which must be assumed optimized to a much higher degree. Another interesting aspect of $\mathbf{P 6 7}$ and the balanced ambipolar properties is that the values were achieved with a bottom gate, bottom contact FET device configuration, ${ }^{[69]}$ whereas most other high performing mobility results were achieved in top gate devices. $\mathbf{P 6 8}$ was also tested with this device configuration, but showed inferior performance $\left(\mu_{\mathrm{h}}=0.3 \mathrm{~cm}^{2} / \mathrm{Vs}, \mu_{\mathrm{e}}=0.05\right.$ $\mathrm{cm}^{2} / \mathrm{Vs}$ ) to that achieved with a top contact configuration. Benzothiadiazole (BT) and its derivatives (P53, P55, and P56) proved to be highly suitable comonomers for the dithienylDPP system and Kronemeijer and co-workers similarly found $\mathbf{P 6 9}$ to perform very well as an ambipolar transistor material. ${ }^{[59]}$ Mobilities of $0.46 \mathrm{~cm}^{2} / \mathrm{Vs}$ and $0.84 \mathrm{~cm}^{2} / \mathrm{Vs}$ were found for holes and electrons, respectively, for a batch of $\mathbf{P 6 9}$ with a moderate molecular weight, while a much higher molecular weight batch afforded a significantly reduced hole mobility $(0.20$ $\mathrm{cm}^{2} / \mathrm{Vs}$ ) and a slightly increased electron mobility of $0.97 \mathrm{~cm}^{2} / \mathrm{Vs}$. The optimum FET properties of $\mathbf{P 6 9}$ were achieved after thermal annealing at $200^{\circ} \mathrm{C}$ and in agreement with previous studies mainly on dithienyl-DPP copolymers the n-type charge transport appeared more sensitive to the annealing temperature than the p-type transport. Here it should be noted that optimized electron mobilities for diselenophenyl-DPP polymers P67-P69 are achieved at significantly lower temperatures than for most other DPP materials, which typically require thermal annealing above $300^{\circ} \mathrm{C}$ to display high electron mobilities. The improved semiconducting properties upon thermal annealing were reflected by a change in the $\pi-\pi$ stacking distance from $3.7 \AA$ to $3.64 \AA$ and this close packing in the solid state correlates well with the XRD data obtained for the dithienyl-analogue P53. P69 is the second example in the diselenophenyl-DPP series where the anticipated improvement in electron transport from a more stable and delocalized LUMO is confirmed experimentally; the best electron mobility 
of $\mathbf{P 6 9}$ is nearly double that of $\mathbf{P 5 3}$, while electron mobilities for the two polymers are comparable.

Two new members of the family of DPP-containing copolymers for high-performing FET applications were introduced by Bronstein and colleagues, who synthesized the dithienothienyl-DPP monomer and subsequently prepared the homopolymer (P70) and the thiophene copolymer (P71). ${ }^{[70]}$ The homopolymer performed much better than the corresponding dithienyl-DPP homopolymer (P7) and showed predominant n-type behavior with an electron mobility of $0.3 \mathrm{~cm}^{2} / \mathrm{Vs}$ and a nearly ten-fold lower hole mobility. P71, on the other hand, was a very good p-type transistor material with a maximum hole mobility of $1.95 \mathrm{~cm}^{2} / \mathrm{Vs}$ and a much lower electron mobility of $0.06 \mathrm{~cm}^{2} / \mathrm{Vs}$. It should be noted that since this report, further studies have improved the electron mobility of P71 to a very respectable $0.9 \mathrm{~cm}^{2} /$ Vs. Bronstein and co-workers speculate that the short repeat unit of P70 brings the bulky alkyl-substituted DPP units too close to each other and thus hinders backbone coplanarity and interchain packing, which could explain the poorer FET performance of P70 relative to P71. Interestingly, the FET mobilities reported for P70 and P71 were achieved without thermal annealing; differential scanning calorimetry (DSC) in both cases showed no evidence of a phase transition and XRD of the thin films showed the materials to be semicrystalline.

\section{Morphological Studies}

X-Ray techniques such as X-ray diffraction (XRD), grazing incidence X-ray diffraction (GIXD) and near-edge X-ray absorption fine structure (NEXAFS) spectroscopy are extremely useful tools in elucidating the structural ordering for $\pi$-conjugated materials. As already discussed briefly in the previous sections, these techniques have also been used frequently to investigate the morphology and ordering of DPP-based materials. Some of the more detailed morphological studies will be examined here to highlight some characteristic 
features of DPP-based donor-acceptor polymers and to discuss some significant differences between closely related DPP polymers.

As depicted in Figure 6, Li and co-workers used XRD to investigate the structural ordering of P17. ${ }^{[29]}$ First, a drop-cast film of P17 was probed with the incident X-ray beam parallel to the substrate and a broad diffraction peak corresponding to a $d$ spacing of $19.9 \AA$ was observed. Thermal annealing of the thin film resulted in a sharper and more intense diffraction peak, while also second and third order peaks appeared in the diffractogram indicative of an increased degree of crystallinity (Figure 6a). Subsequently, the authors prepared a stack of multiple polymer thin films and performed the XRD experiment both with the incident X-ray beam parallel (Figure 6c-d) and perpendicular (Figure 6e-f) to the stack. A remarkable difference was observed: when the stack was probed in the parallel configuration, a diffraction peak corresponding to a $d$ spacing of $19.9 \AA$ was observed in agreement with the initial experiment, but when probed in the perpendicular configuration, the dominant diffraction peak corresponded to a $d$ spacing of $3.75 \AA$. This set of experiments clearly implies the presence of crystalline domains of $\mathbf{P 1 7}$ predominantly aligned with an edge-on molecular orientation with a lamellar spacing of $19.9 \AA$ A extending in the direction perpendicular to the substrate and a $\pi-\pi$ spacing of $3.75 \AA$ extending parallel to the substrate. Zhang and co-workers came to the same conclusion when they - in their comparison of P16, P17 and P27 - examined P17 using GIXD and NEXAFS spectroscopy. ${ }^{[25]}$ With a twodimensional detector, the GIXD experiment can afford both in-plane and out-of-plane $d$ spacings. Using this technique, Zhang and co-workers found both P17 and P27 to align with a preferential edge-on molecular orientation as illustrated in Figure 7a; the as-cast films showed some tilted and face-on domains as well, whereas the annealed films (Figure 7b) oriented almost exclusively edge-on. P16, on the other hand, was found to give less ordered domains with a preference for face-on orientation when examined as-cast as illustrated in 
Figure 7c. Upon thermal annealing, the structural order increased and both edge-on and faceon domains were detected (Figure 7d). These results for P16, P17 and P27 were corroborated by NEXAFS spectroscopy, which was furthermore used to compare the morphologies of the top and bottom surfaces of the delaminated thin films; this is of relevance to the FET device configuration (top gate or bottom gate). Thin films of P17 and P27 were found to have similar top and bottom surfaces with orientations as discussed above, whereas P16 appeared to be more disordered at the top surface than at the bottom surface. Further surface analysis was carried out with atomic force microscopy (AFM), which revealed clear fibrillar features for P17 and P27, while a more nodular surface morphology was observed for P16 (Figure 8). The strong preference for an edge-on orientation for P17 and P27 made it possible for Zhang and co-workers to clearly elucidate the variation in $\pi-\pi$ stacking direction with dark-field transmission electron microscopy (DF-TEM) and an in-plane liquid crystalline texture was found for these two polymers.

Yuen and colleagues also investigated a series of three closely related dithienyl-DPP polymers (P24, P55 and P57) with XRD and GIXD and found the phenyl derivative (P24) to orient face-on, while the BT and BBT derivatives showed a preferential edge-on molecular orientation. This conclusion was reached solely by examining the lamellar diffraction peaks as no $\pi-\pi$ stacking was observed for any of the three polymers, which are obviously less crystalline than the series studied by Zhang. The lamellar $d$ spacings were in all three cases on the order of 24 - $25 \AA$, which corresponds well with the long alkyl chains used to solubilize the rigid polymer backbone.

Sonar and co-workers have reported both on the dithienyl-DPP copolymer with naphthalene (P11) and the corresponding difuranyl-DPP analogue (P60). ${ }^{[19,63]}$ X-ray analysis was performed on flakes of both materials and the data clearly indicate that the thiophenecontaining P11 has stronger $\pi-\pi$ interactions (3.82 A spacing) than the furan derivative P60 
(4.18 ̊ spacing). Lamellar $d$ spacings of $20.05 \AA$ and $17.58 \AA$ respectively show that the volumes of the two unit cells are similar despite the variation in $\pi-\pi$ stacking distance. The much increased $\pi-\pi$ distance of $\mathbf{P 6 0}$ versus P11 is most likely the major reason for the observed decrease in hole mobility by nearly one order of magnitude. A similar relationship was observed when comparing the two studies of P17 and P64 by Li and co-workers. ${ }^{[29,66]}$ As previously mentioned, the thiophene analogue P17 shows a high degree of crystallinity with an edge-on orientation and a $\pi-\pi$ spacing of $3.75 \AA$, whereas the furan analogue (P64) is less ordered with both edge-on, face-on and tilted domains and a much larger $\pi$ - $\pi$ stacking distance of $4.4 \AA$ A. Surprisingly, in this case, $\mathbf{P 6 4}$ actually has the better FET performance of the two polymers with a hole mobility of $1.54 \mathrm{~cm}^{2} / \mathrm{Vs}$. With these contradicting trends between $\pi-\pi$ distances and charge transport properties, it is obvious that other parameters such as molecular weight, frontier energy levels, and trace impurities also play important roles in the optimization of charge transport. Moreover, it is not clear from the energyminimized conformations (Figure $2 \mathrm{~b}$ and 5a) why difuranyl-DPP copolymers tend to pack with a larger $\pi-\pi$ distance in the solid state than the corresponding dithienyl-DPP materials. Shahid and Heeney similarly used wide-angle X-ray scattering (WAXS) to compare the two diselenophenyl-DPP polymers $\mathbf{P 6 7}$ and $\mathbf{P 6 8}$. The experiments showed that a thin film of $\mathbf{P 6 7}$, which is the all-selenophene analogue of $\mathbf{P 1 6}$, contained both edge-on and face-on oriented domains. In contrast, $\mathbf{P 6 8}$, which is the diselenophenyl-DPP analogue of P27, showed only lamellar packing indicative of an exclusive edge-on molecular orientation relative to the substrate. These results are in excellent agreement with the observations regarding structural order and orientation made by Zhang and co-workers on the thiophene derivatives; and clearly indicate that the replacement of one or more thiophene units with selenophenes leaves the tendency for a specific molecular orientation unaffected. The comparison of polymers $\mathbf{P 5 3}$ and $\mathbf{P 6 9}$ represents another opportunity to investigate the role of 
selenophene versus thiophene. While Sonar and colleagues, by means of XRD, found the thiophene derivative P53 to predominantly orient in an edge-on fashion, Kronemeijer and coworkers used GIXD and concluded that both P53 and P69 showed bimodal distributions of edge-on and face-on oriented crystalline domains in the solid state. ${ }^{[57,59]}$ In Kronemeijer's study, essentially identical values were found for the lamellar spacings and the $\pi-\pi$ stacking distances of the two polymers indicating that the chalcogen atom has little influence on the solid state packing.

Some general trends related to the solid state morphology, which are commonly observed for these DPP polymers, are that an increased degree of crystallinity typically is associated with an increase in charge carrier mobility and that a shortened $\pi$ - $\pi$ stacking distance typically is associated with an increase in charge carrier mobility as well. Both observations are not unexpected. It is interesting to note, nonetheless, that very efficient charge carrier transport has been observed for 1) polymers with apparently weak $\pi-\pi$ interactions, 2) polymers with a preferred face-on orientation relative to the substrate (in contrast to most thiophene based polymers), and 3) polymers with little or no evidence of structural order.

\section{Ambipolarity}

Much attention has recently been focused on aspects relating to n-type charge transport and ambipolar charge transport in $\pi$-conjugated materials. This is not only due to an increased interest from an academic point of view, but also driven by the fact that ambipolarity significantly broadens the range of potential electronic devices and circuitry that can be fabricated with these semiconducting materials.

A recurring theme for the best performing electron transport materials discussed so far in this progress report is that high-temperature annealing treatments have often been necessary to reach the optimum mobilities and that the electron transport properties appeared 
much more sensitive to the thermal annealing conditions than the hole transport properties, which in most cases plateaus at a much lower annealing temperature. This is exemplified by the thienothiophene-containing polymer P27, which showed an electron mobility of 0.02 $\mathrm{cm}^{2} / \mathrm{Vs}$ as-cast and also after $200^{\circ} \mathrm{C}$ annealing, but reached a mobility of $1.56 \mathrm{~cm}^{2} / \mathrm{Vs}$ after a $320^{\circ} \mathrm{C}$ annealing step (and solvent-cleaning of the electrodes). ${ }^{[8]} \mathrm{A}$ similar trend was observed by Mohebbi and co-workers for P49, which reached an electron mobility of 0.25 $\mathrm{cm}^{2} / \mathrm{Vs}$ only after $320^{\circ} \mathrm{C} .{ }^{[53]}$ In these cases, little change in morphology and structural order was observed when increasing the annealing temperature from the $200^{\circ} \mathrm{C}$ range to the more extreme conditions around $320^{\circ} \mathrm{C}$ needed for optimum n-type semiconducting properties. This has led Chen and co-workers, among others, to believe that the improved FET properties at high-temperature annealing conditions are caused by evaporation of electron-trapping impurities from the polymer film and improvement of polymer/electrode contacts. ${ }^{[8,52]}$ Another common feature of the high-performing n-type semiconducting polymers discussed in this progress report is the incorporation of additional electron-poor units. This approach has been highly successful for dithienyl-DPP polymers using electron-poor comonomers such as BT $\left(\mathbf{P 5 3}, \mu_{\mathrm{e}}=0.57 \mathrm{~cm}^{2} / \mathrm{Vs}\right)$ and BBT $\left(\mathbf{P 5 6}, \mu_{\mathrm{e}}=1.36 \mathrm{~cm}^{2} / \mathrm{Vs}\right)$ and also for the corresponding difuranyl- and diselenophenyl-DPP systems with BT $\left(\mathbf{P 6 6}, \mu_{\mathrm{e}}=0.56\right.$ $\mathrm{cm}^{2} /$ Vs and P69, $\mu_{\mathrm{e}}=0.97 \mathrm{~cm}^{2} / \mathrm{Vs}$ ). These very electron-poor polymers will obviously have low-lying LUMO energy levels (Table 2 and 3) allowing for efficient electron injection, which is a first prerequisite for good n-type transport with conventional transistor electrodes, and good operational stability. Additionally, Kronemeijer and colleagues have identified another important feature that they speculate to be related to the high electron mobility of P69. ${ }^{[59]}$ As depicted in Figure 9, both the HOMO and the LUMO of $\mathbf{P 6 9}$ are predicted to be extensively delocalized along the entire polymer backbone, which is in contrast to most donor-acceptor type copolymers, where the HOMO is typically delocalized along the 
conjugated backbone while the LUMO is predominantly localized on the electron-poor acceptor units of the polymer. In this case, the delocalized LUMO of P69 is naturally thought to play a role in the highly effective inter- and intramolecular electron transport. Noticeably, the selenium atom of the selenophene unit does also participate in the LUMO of P69, while a similar contribution to the LUMO is generally not seen for the corresponding thiophene derivatives. The participation of the selenium atom is thought to stabilize the LUMO and facilitate electron injection. ${ }^{[69]}$ These expected advantages of selenophene-containing materials for n-type semiconductors are adequately supported by the excellent electron mobilities observed for most of the selenophene-containing DPP polymers reported herein (P21-P22, Table 2 and P67-P69, Table 3).

\section{Conclusions and Outlook}

In this progress report, we have discussed over 80 different polymers containing the DPP moiety and more than half of these exhibited an electron and/or hole mobility greater than $0.01 \mathrm{~cm}^{2} / \mathrm{Vs}$. Of the remaining lower-performing polymers, a significant number of these can probably be greatly improved by achieving a more optimal molecular weight (with adaptation of the alkyl substitution) and/or reaching the required purity and/or using the correct deposition process and/or the optimum device architecture. This clearly underlines the crucial impact of these parameters and also explains why it is still difficult to compare results obtained with polymers synthesized or measured in different labs. Nevertheless, some clear trends are emerging from this study. It is often found in other classes of semiconducting polymers, that there is a correlation between the $\pi-\pi$ intermolecular distances and the measured mobility. Similarly, for DPP-based materials, the performance of diphenyl-DPPs suffer from the larger dihedral angle between the DPP moiety and the phenyl unit which prevents optimal packing of polymer chains while the furan, selenophene and thiophene derivatives in many cases display high performance (mobilities in excess of $1 \mathrm{~cm}^{2} / \mathrm{Vs}$ ) mainly 
attributed to their relatively coplanar structures, which allow for stronger intermolecular interactions.

The presence of long branched alkyl chains on the DPP unit appears to have limited impact on the electrical performance, whereas the addition of alkyl chains on other locations along the backbone often induces detrimental steric hindrance.

To achieve a high electron mobility, a low lying and widely delocalized LUMO is beneficial. It was also observed that high-temperature annealing (over $200^{\circ} \mathrm{C}$ ) is required to achieve high n-type mobilities in most cases, and it will be important from a commercialization point of view to reduce this annealing temperature to align with manufacturing processes that utilize plastic substrates. In conclusion, DPP-containing polymers have the synthetic flexibility to incorporate a great variety of building blocks in order to tune the electronic properties and provide high performance polymers for FET applications.

\section{Acknowledgements}

This work was in part carried out with financial support from SUPERGEN, EC FP7 Project X10D and EC FP7 Project ONE-P, with support from the Centre for Plastic Electronics at Imperial College and the International Collaborative Research Program of Gyeonggi-do, Korea.

Received: ((will be filled in by the editorial staff))

Revised: ((will be filled in by the editorial staff)) Published online: ((will be filled in by the editorial staff)) 
[1] A. Tsumura, H. Koezuka, T. Ando, Appl. Phys. Lett. 1986, 49, 1210.

[2] A. A. Virkar, S. Mannsfeld, Z. Bao, N. Stingelin, Adv. Mater. 2010, 22, 3857.

[3] A. B. Tamayo, M. Tantiwiwat, B. Walker, T.-Q. Nguyen, J. Phys. Chem. C 2008, 112, 15543; H. Langhals, S. Demmig, T. Potrawa, J. Prakt. Chem. 1991, 333, 733.

[4] M. Turbiez, R. A. J. Janssen, M. M. Wienk, H.-J. Kirner, M. Düggeli, B. Tieke, Y. Zhu, 2008.

[5] M. M. Wienk, M. Turbiez, J. Gilot, R. A. J. Janssen, Adv. Mater. 2008, 20, 2556.

[6] L. Bürgi, M. Turbiez, R. Pfeiffer, F. Bienewald, H.-J. Kirner, C. Winnewisser, $A d v$. Mater. 2008, 20, 2217.

[7] H. Chen, Y. Guo, G. Yu, Y. Zhao, J. Zhang, D. Gao, H. Liu, Y. Liu, Adv. Mater. 2012, n/a.

[8] Z. Chen, M. J. Lee, R. Shahid Ashraf, Y. Gu, S. Albert-Seifried, M. Meedom Nielsen, B. Schroeder, T. D. Anthopoulos, M. Heeney, I. McCulloch, H. Sirringhaus, Adv. Mater. 2012, 24, 647.

[9] W. K. Chan, Y. Chen, Z. Peng, L. Yu, J. Am. Chem. Soc. 1993, 115, 11735; L. Yu, Y. Chen, W. K. Chan, Z. Peng, Appl. Phys. Lett. 1994, 64, 2489.

[10] P.-T. Wu, F. S. Kim, S. A. Jenekhe, Chem. Mater. 2011, 23, 4618.

[11] G. Zhang, H. Xu, K. Liu, Y. Li, L. Yang, M. Yang, Synth. Met. 2010, 160, 1945.

[12] W. Li, T. Lee, S. J. Oh, C. R. Kagan, ACS Appl. Mater. Interfaces 2011, 3, 3874.

[13] C. Kanimozhi, P. Balraju, G. D. Sharma, S. Patil, J. Phys. Chem. B 2010, 114, 3095.

[14] L. Chen, D. Deng, Y. Nan, M. Shi, P. K. L. Chan, H. Chen, J. Phys. Chem. C 2011, $115,11282$.

[15] C. L. Chochos, S. A. Choulis, Prog. Polym. Sci. 2011, 36, 1326.

[16] A. P. Zoombelt, S. G. J. Mathijssen, M. G. R. Turbiez, M. M. Wienk, R. A. J. Janssen, J. Mater. Chem. 2010, 20, 2240. 
[17] Y. Li, B. Sun, P. Sonar, S. P. Singh, Org. Electron. 2012, 13, 1606.

[18] J. C. Bijleveld, V. S. Gevaerts, D. Di Nuzzo, M. Turbiez, S. G. J. Mathijssen, D. M. de Leeuw, M. M. Wienk, R. A. J. Janssen, Adv. Mater. 2010, 22, E242.

[19] P. Sonar, S. P. Singh, Y. Li, Z.-E. Ooi, T.-j. Ha, I. Wong, M. S. Soh, A. Dodabalapur, Energy Environ. Sci. 2011, 4, 2288.

[20] T.-J. Ha, P. Sonar, A. Dodabalapur, Appl. Phys. Lett. 2011, 98, 253305.

[21] Y. Zou, D. Gendron, R. Badrou-Aich, A. Najari, Y. Tao, M. Leclerc, Macromolecules 2009, 42, 2891.

[22] N. Allard, R. B. Aich, D. Gendron, P.-L. T. Boudreault, C. Tessier, S. Alem, S.-C. Tse, Y. Tao, M. Leclerc, Macromolecules 2010, 43, 2328.

[23] H. Sirringhaus, P. J. Brown, R. H. Friend, M. M. Nielsen, K. Bechgaard, B. M. W. Langeveld-Voss, A. J. H. Spiering, R. A. J. Janssen, E. W. Meijer, P. Herwig, D. M. de Leeuw, Nature 1999, 401, 685; I. McCulloch, M. Heeney, C. Bailey, K. Genevicius, I. MacDonald, M. Shkunov, D. Sparrowe, S. Tierney, R. Wagner, W. Zhang, M. L. Chabinyc, R. J. Kline, M. D. McGehee, M. F. Toney, Nat. Mater. 2006, 5, 328.

[24] J. C. Bijleveld, A. P. Zoombelt, S. G. J. Mathijssen, M. M. Wienk, M. Turbiez, L. D. M. de, R. A. J. Janssen, J. Am. Chem. Soc. 2009, 131, 16616.

[25] X.-R. Zhang, L. J. Richter, D. M. DeLongchamp, R. J. Kline, M. R. Hammond, I. McCulloch, M. Heeney, R. S. Ashraf, J. N. Smith, T. D. Anthopoulos, B. Schroeder, Y. H. Geerts, D. A. Fischer, M. F. Toney, J. Am. Chem. Soc. 2011, 133, 15073.

[26] J. S. Lee, S. K. Son, S. Song, H. Kim, D. R. Lee, K. Kim, M. J. Ko, D. H. Choi, B. Kim, J. H. Cho, Chem. Mater. 2012, 24, 1316.

[27] R. J. Kline, M. D. McGehee, E. N. Kadnikova, J. Liu, J. M. J. Frechet, Adv. Mater. 2003, $15,1519$.

[28] J. S. Ha, K. H. Kim, D. H. Choi, J. Am. Chem. Soc. 2011, 133, 10364. 
[29] Y. Li, P. Sonar, S. P. Singh, M. S. Soh, M. van Meurs, J. Tan, J. Am. Chem. Soc. 2011, 133, 2198.

[30] C. B. Nielsen, I. McCulloch, Prog. Polym. Sci. 2012.

[31] J.-H. Tsai, W.-Y. Lee, W.-C. Chen, C.-Y. Yu, G.-W. Hwang, C. Ting, Chem. Mater. 2010, 22, 3290.

[32] W.-H. Lee, S. K. Son, K. Kim, S. K. Lee, W. S. Shin, S.-J. Moon, I.-N. Kang, Macromolecules 2012, 45, 1303.

[33] M. Heeney, W. Zhang, D. J. Crouch, M. L. Chabinyc, S. Gordeyev, R. Hamilton, S. J. Higgins, I. McCulloch, P. J. Skabara, D. Sparrowe, S. Tierney, Chem. Commun. 2007, 5061. [34] H.-W. Lin, W.-Y. Lee, W.-C. Chen, J. Mater. Chem. 2012, 22, 2120.

[35] J. D. Yuen, J. Fan, J. Seifter, B. Lim, R. Hufschmid, A. J. Heeger, F. Wudl, J. Am. Chem. Soc. 2011, 133, 20799.

[36] B. Lim, J.-S. Yeo, D. Khim, D.-Y. Kim, Macromol. Rapid Commun. 2011, 32, 1551.

[37] J. C. Bijleveld, R. A. M. Verstrijden, M. M. Wienk, R. A. J. Janssen, J. Mater. Chem. 2011, 21, 9224.

[38] Y. Li, S. P. Singh, P. Sonar, Adv. Mater. 2010, 22, 4862.

[39] J. Min, B. Peng, Y. Wen, Z.-G. Zhang, M. Zhang, J. Zhang, Q. Xie, Y. Liu, Y. Li, Synth. Met. 2011, 161, 1832.

[40] M. Heeney, C. Bailey, S. Tierney, W. Zhang, I. McCulloch, U.S. Patent Number: $7,524,922,2009$.

[41] Z. Li, Y. Zhang, S.-W. Tsang, X.-M. Du, J.-Y. Zhou, Y. Tao, J.-F. Ding, J. Phys. Chem. C 2011, 115, 18002.

[42] L. Dou, J. You, J. Yang, C.-C. Chen, Y. He, S. Murase, T. Moriarty, K. Emery, G. Li, Y. Yang, Nat. Photonics 2012, 6, 180. 
[43] M. Yuan, A. H. Rice, C. K. Luscombe, J. Polym. Sci., Part A: Polym. Chem. 2011, $49,701$.

[44] M.-J. Zhang, Y.-P. Sun, X. Guo, C.-H. Cui, Y.-J. He, Y.-F. Li, Macromolecules 2011, 44,7625 .

[45] T. L. Nelson, T. M. Young, J. Liu, S. P. Mishra, J. A. Belot, C. L. Balliet, A. E. Javier, T. Kowalewski, R. D. McCullough, Adv. Mater. 2010, 22, 4617.

[46] E. Zhou, Q. Wei, S. Yamakawa, Y. Zhang, K. Tajima, C. Yang, K. Hashimoto, Macromolecules 2010, 43, 821.

[47] J. W. Jung, F. Liu, T. P. Russell, W. H. Jo, Energy Environ. Sci. 2012.

[48] A. V. Patil, W.-H. Lee, K. Kim, H. Park, I. N. Kang, S.-H. Lee, Polym. Chem. 2011, 2, 2907.

[49] S.-Y. Ku, C. D. Liman, D. J. Burke, N. D. Treat, J. E. Cochran, E. Amir, L. A. Perez, M. L. Chabinyc, C. J. Hawker, Macromolecules 2011, 44, 9533.

[50] X. Wang, H. Luo, Y. Sun, M. Zhang, X. Li, G. Yu, Y. Liu, Y. Li, H. Wang, J. Polym. Sci., Part A: Polym. Chem. 2012, 50, 371.

[51] Y. Sun, S.-C. Chien, H.-L. Yip, K.-S. Chen, Y. Zhang, J. A. Davies, F.-C. Chen, B. Lin, A. K. Y. Jen, J. Mater. Chem. 2012, 22.

[52] R. S. Ashraf, Z. Chen, D. S. Leem, H. Bronstein, W. Zhang, B. Schroeder, Y. Geerts, J. Smith, S. Watkins, T. D. Anthopoulos, H. Sirringhaus, J. C. de Mello, M. Heeney, I. McCulloch, Chem. Mater. 2011, 23, 768.

[53] A. R. Mohebbi, J. Yuen, J. Fan, C. Munoz, M. f. Wang, R. S. Shirazi, J. Seifter, F. Wudl, Adv. Mater. 2011, 23, 4644.

[54] J. B. Lee, K. H. Kim, C. S. Hong, D. H. Choi, J. Polym. Sci., Part A: Polym. Chem. 2012, 50, 2809.

[55] J. Lee, S. Cho, C. Yang, J. Mater. Chem. 2011, 21, 8528. 
[56] H. N. Tsao, D. M. Cho, I. Park, M. R. Hansen, A. Mavrinskiy, D. Y. Yoon, R. Graf, W. Pisula, H. W. Spiess, K. Müllen, J. Am. Chem. Soc. 2011, 133, 2605.

[57] P. Sonar, S. P. Singh, Y. Li, M. S. Soh, A. Dodabalapur, Adv. Mater. 2010, 22, 5409.

[58] S. Cho, J. Lee, M. Tong, J. H. Seo, C. Yang, Adv. Funct. Mater. 2011, 21, 1910.

[59] A. J. Kronemeijer, E. Gili, M. Shahid, J. Rivnay, A. Salleo, M. Heeney, H.

Sirringhaus, Adv. Mater. 2012, 24, 1558.

[60] T.-J. Ha, P. Sonar, S. P. Singh, A. Dodabalapur, IEEE Trans. Electron Devices 2012, $59,1494$.

[61] J. Lee, S. Cho, J. H. Seo, P. Anant, J. Jacob, C. Yang, J. Mater. Chem. 2012, 22.

[62] W. Hong, B. Sun, H. Aziz, W.-T. Park, Y.-Y. Noh, Y. Li, Chem. Commun. 2012, 48, 8413.

[63] P. Sonar, S. P. Singh, E. L. Williams, Y. Li, M. S. Soh, A. Dodabalapur, J. Mater. Chem. 2012, 22.

[64] J. C. Bijleveld, B. P. Karsten, S. G. J. Mathijssen, M. M. Wienk, D. M. de Leeuw, R. A. J. Janssen, J. Mater. Chem. 2011, 21, 1600.

[65] A. T. Yiu, P. M. Beaujuge, O. P. Lee, C. H. Woo, M. F. Toney, J. M. J. Fréchet, J. Am. Chem. Soc. 2011, 134, 2180.

[66] Y. Li, P. Sonar, S. P. Singh, W. Zeng, M. S. Soh, J. Mater. Chem. 2011, 21, 10829.

[67] P. Sonar, J.-M. Zhuo, L.-H. Zhao, K.-M. Lim, J. Chen, A. J. Rondinone, S. P. Singh, L.-L. Chua, P. K. H. Ho, A. Dodabalapur, J. Mater. Chem. 2012, 22, 17284.

[68] P. Sonar, T. R. B. Foong, S. P. Singh, Y. Li, A. Dodabalapur, Chem. Commun. 2012, $48,8383$.

[69] M. Shahid, T. McCarthy-Ward, J. Labram, S. Rossbauer, E. B. Domingo, S. E. Watkins, N. Stingelin, T. D. Anthopoulos, M. Heeney, Chem. Sci. 2012, 3, 181. 
[70] H. Bronstein, Z. Chen, R. S. Ashraf, W. Zhang, J. Du, J. R. Durrant, P. Shakya

Tuladhar, K. Song, S. E. Watkins, Y. Geerts, M. M. Wienk, R. A. J. Janssen, T. Anthopoulos,

H. Sirringhaus, M. Heeney, I. McCulloch, J. Am. Chem. Soc. 2011, 133, 3272. 
<smiles>[R]N1C(=O)C2=C(c3ccc(C4CCC(C)CC4)cc3)N([R])C(=O)C2=C1c1ccc(C)cc1</smiles>

Figure 1. General structure of copolymers containing the diphenyl-DPP (3,6-diphenyl-2,5diketopyrrolo[3,4-c]pyrrole) unit.
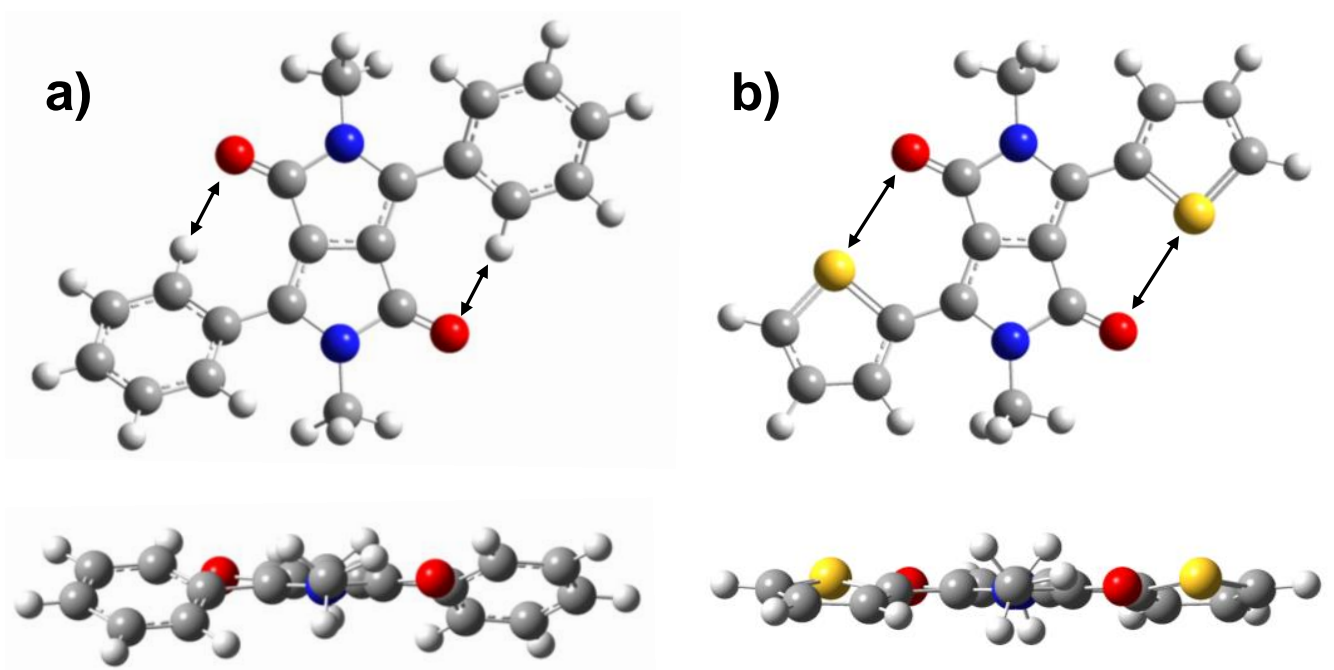

Figure 2. Gaussian-predicted (B3LYP/6-31G* level) conformations of diphenyl-DPP (a) and dithienyl-DPP (b) in front view (top) and side view (bottom) illustrating the increased torsional backbone twist $\left(27^{\circ}\right.$ dihedral angle $)$ in diphenyl-DPP relative to dithienyl-DPP $\left(12^{\circ}\right.$ dihedral angle).<smiles></smiles>

Figure 3. General structure of copolymers containing the dithienyl-DPP (3,6-dithienyl-2,5diketopyrrolo[3,4-c]pyrrole) unit.

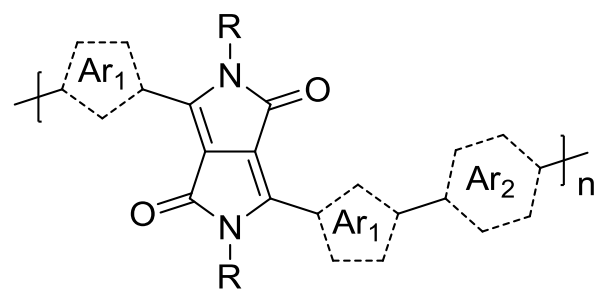

Figure 4. General structure of copolymers containing the diaryl-DPP (3,6-diaryl-2,5diketopyrrolo[3,4-c]pyrrole) unit. 
a)
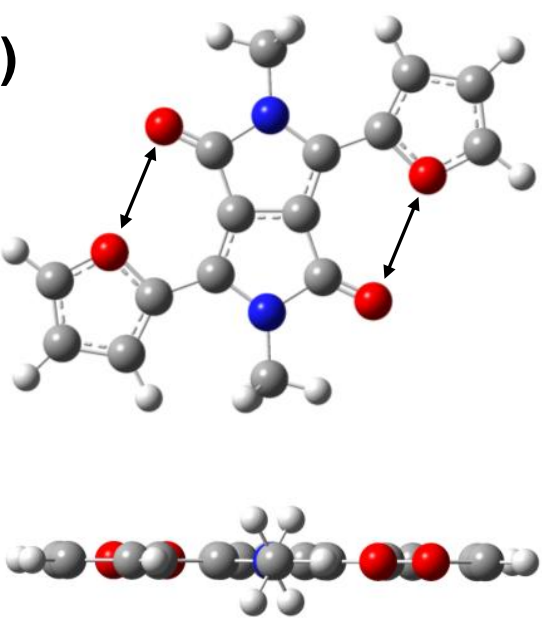
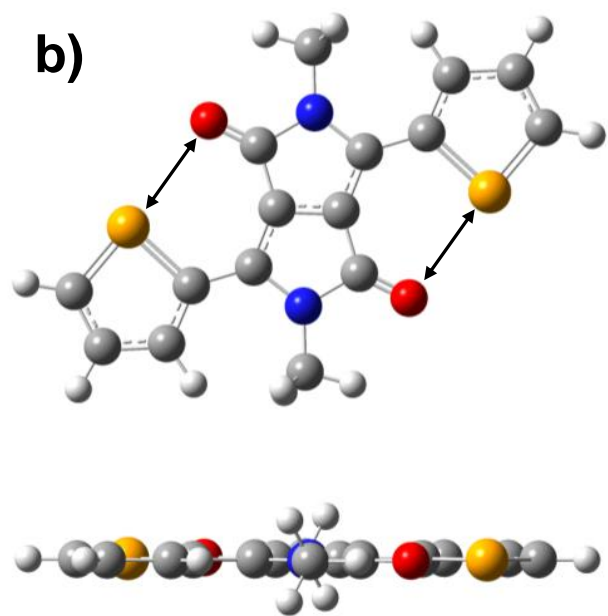

Figure 5. Gaussian-predicted (B3LYP/6-31G* level) conformations of difuranyl-DPP (a) and diselenophenyl-DPP (b) in front view (top) and side view (bottom).
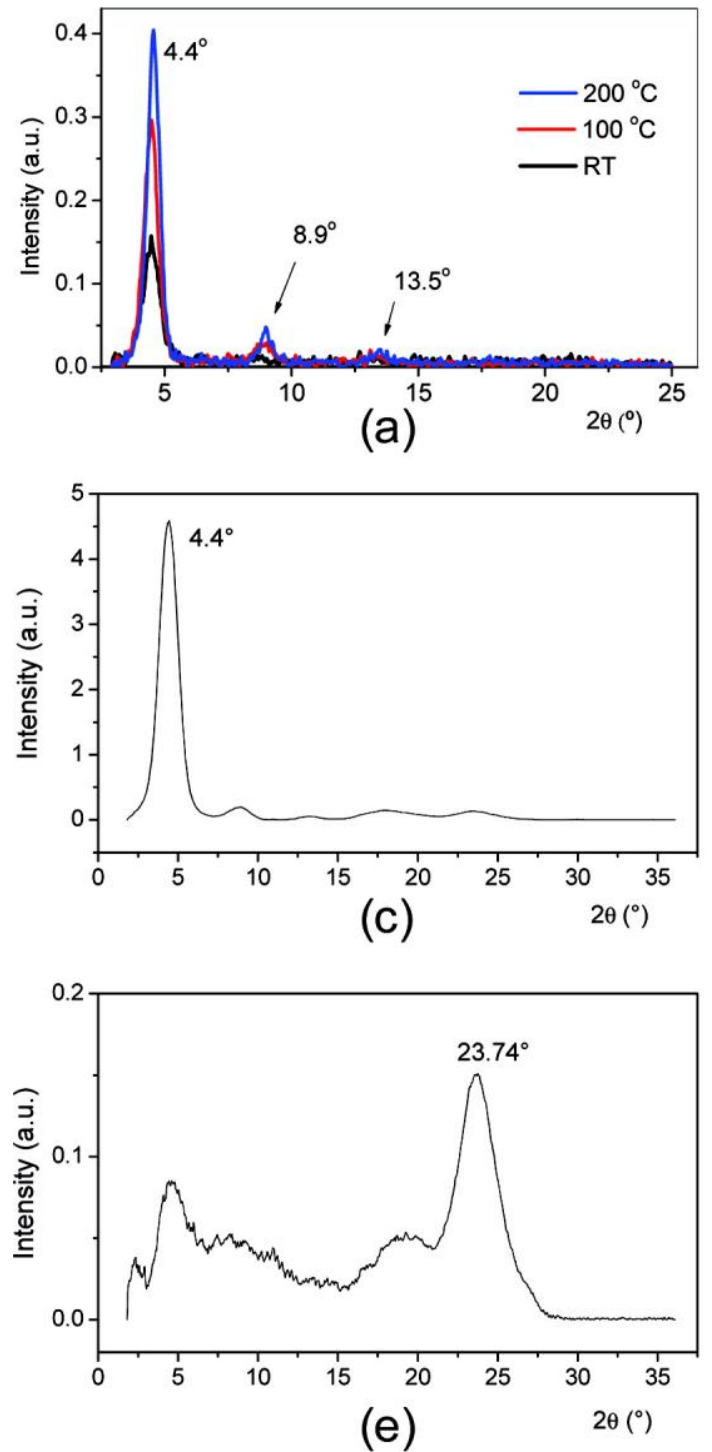

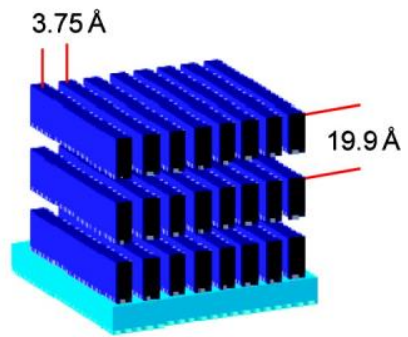

(b)

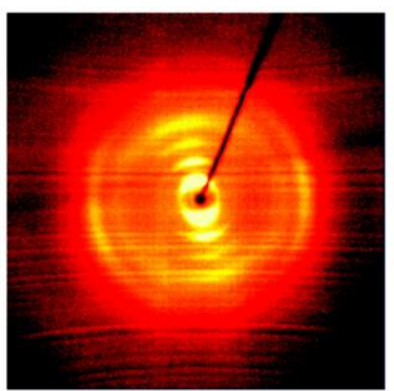

(d)

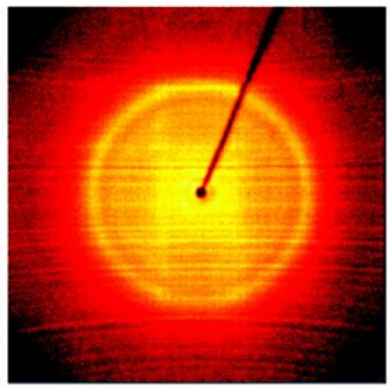

(f)

Figure 6. XRD intensity graphs of drop-cast P17 thin films (100 nm) on OTS-modified $\mathrm{Si} / \mathrm{SiO} 2$ substrates annealed at different temperatures (a). Illustrative lamellar structures of P17 in the thin film (b). Respective 2-D XRD image and pattern intensity graph obtained 
with the incident X-ray parallel to the thin film stack (c, d). Respective 2-D XRD image and pattern intensity graph obtained with the incident X-ray perpendicular to the thin film stack (e, f). Reproduced with permission from ref. ${ }^{[29]}$. Copyright 2011 American Chemical Society.
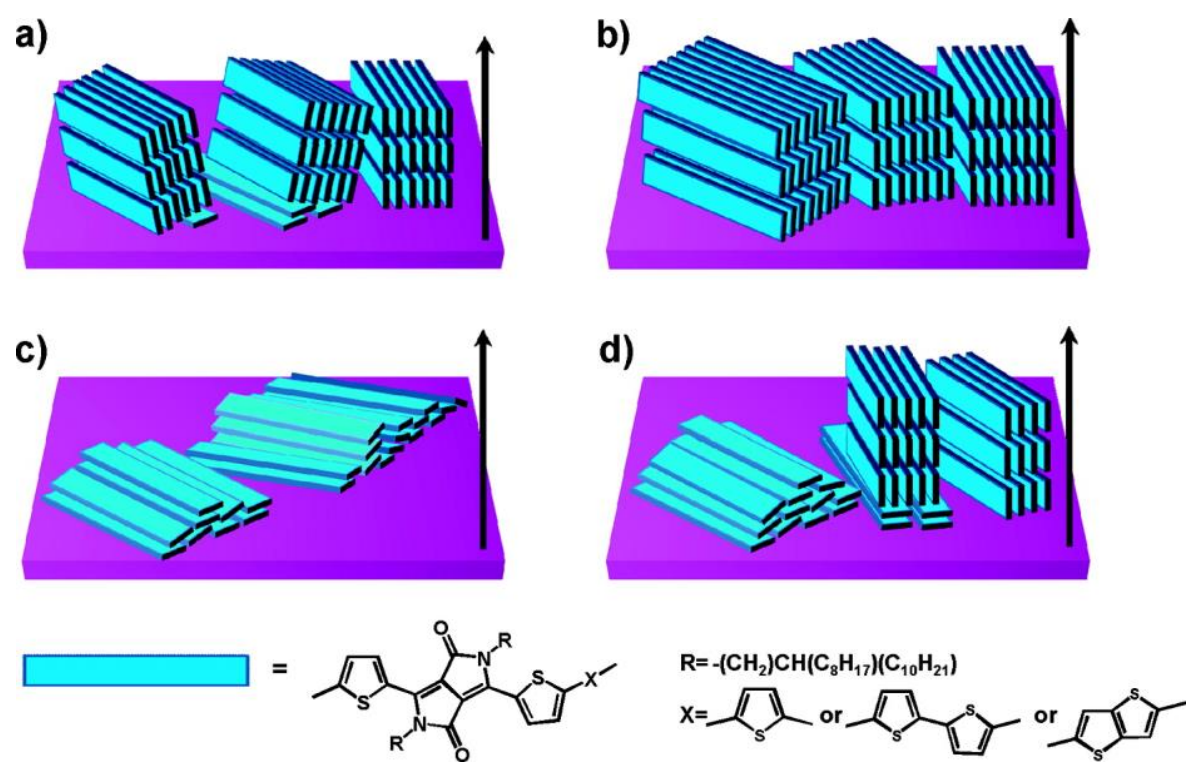

Figure 7. Illustrations for the molecular packing motifs in (a) as-cast P17 and P27 films; (b) annealed P17 and P27 films; (c) as-cast P16 film; and (d) annealed P16 film. The arrows denote the film surface normal direction. Reproduced with permission from ref. ${ }^{[25]}$. Copyright 2011 American Chemical Society.
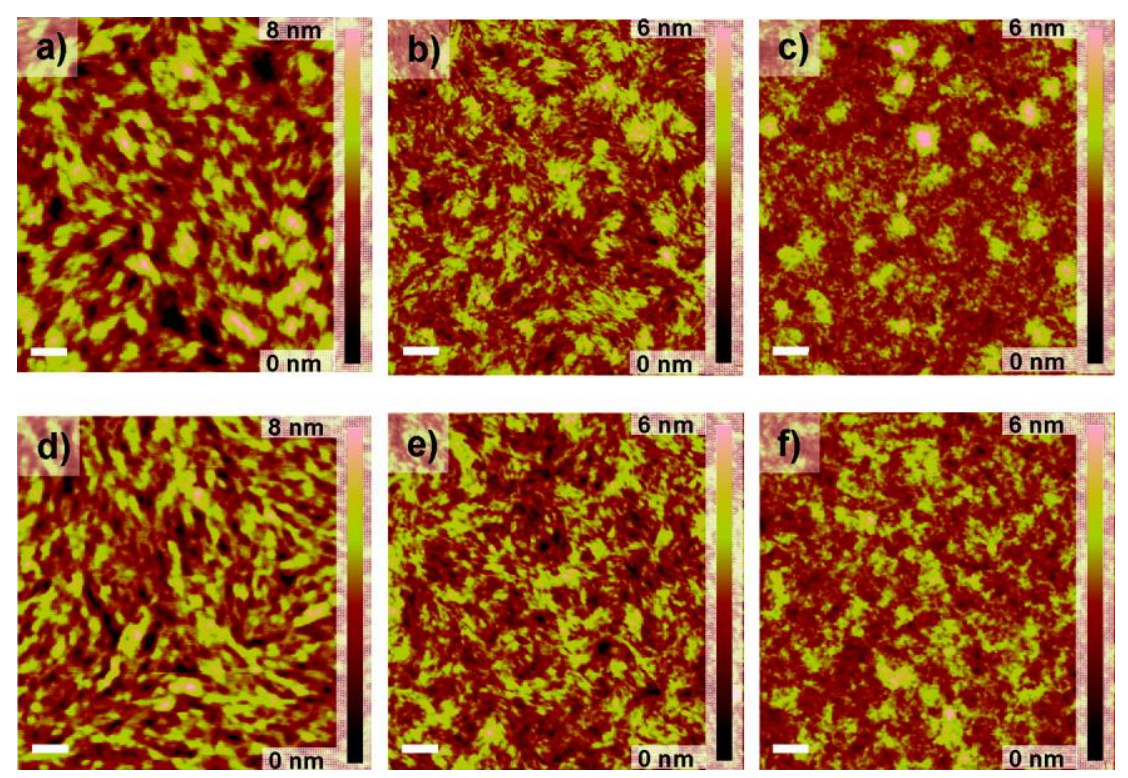

Figure 8. Tapping mode AFM height images of polymer films. (a) P27, as-cast; (b) P17, ascast; (c) P16, as-cast; (d) P27, annealed; (e) P17, annealed; (f) P16, annealed. All scale bars denote $200 \mathrm{~nm}$. Reproduced with permission from ref. ${ }^{[25]}$. Copyright 2011 American Chemical Society. 

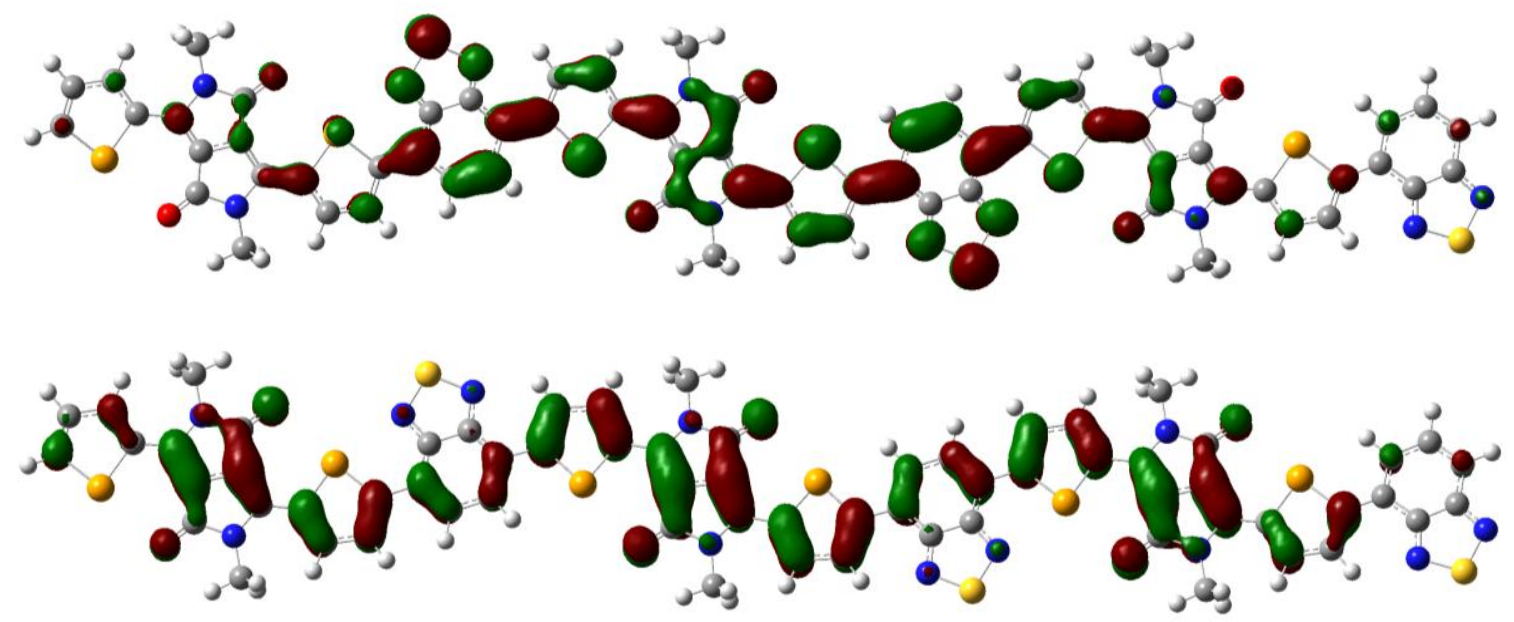

Figure 9. Energy-minimized structure (B3LYP/6-31G(d)) of a P69 trimer (where $\mathrm{R}=\mathrm{CH}_{3}$ ) with a visualization of the LUMO and HOMO molecular orbitals at the top and bottom, respectively. Green and red represent the isosurfaces of opposite phase of the wavefunctions and demonstrate the delocalization of both the HOMO and LUMO. Reproduced with permission from ref. ${ }^{[59]}$. Copyright 2012 WILEY-VCH Verlag GmbH \& Co. KGaA, Weinheim. 
Table 1. Diphenyl-DPP Polymers

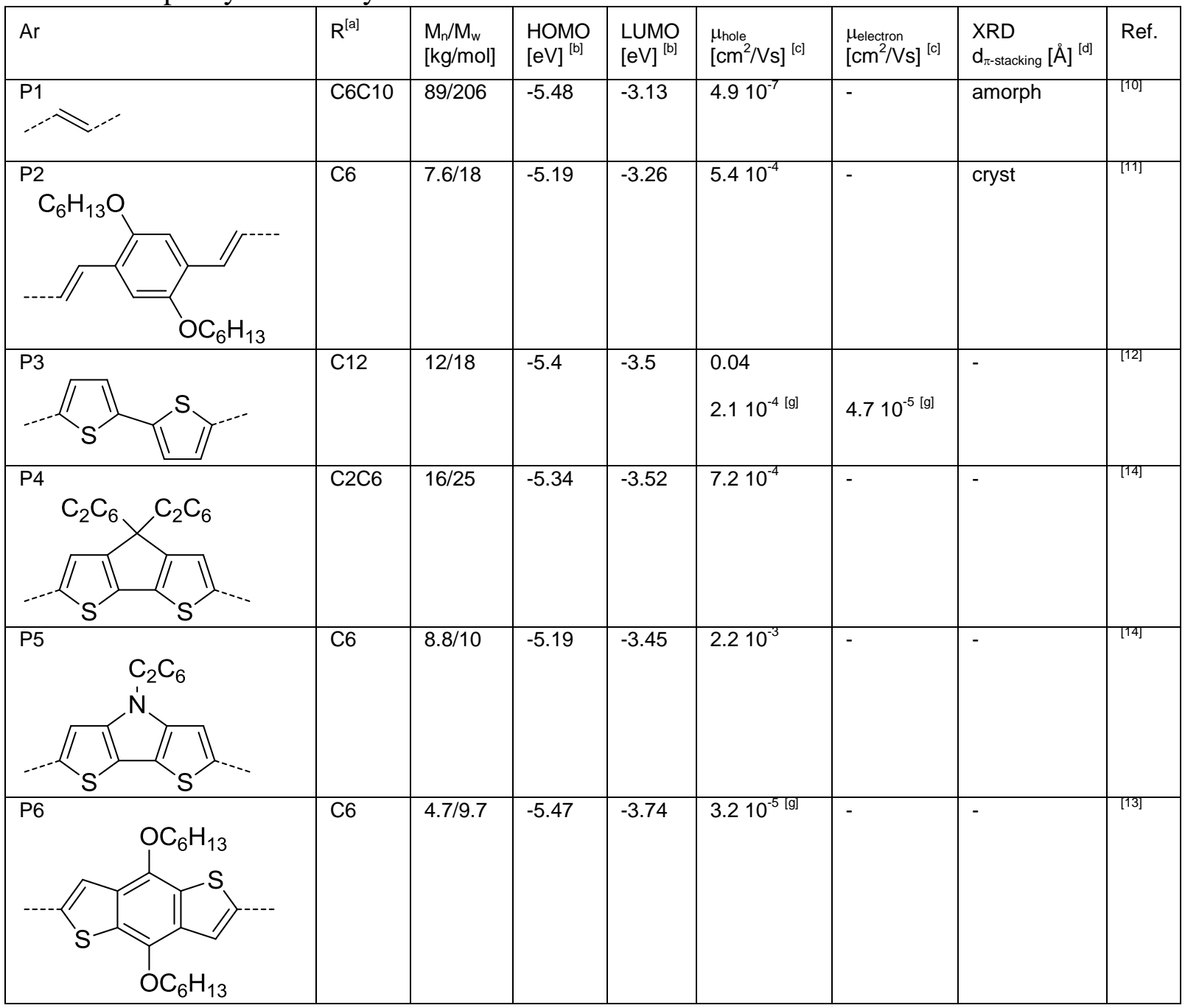

[a] The following acronyms are used for branched alkyl chains: C2C6: 2-ethyl-1-hexyl, C4C8: 2-butyl-1-octyl, C6C10: 2-hexyl-1-decyl, C8C12: 2-octyl-1-dodecyl, C10C14: 2decyl-1-tetradecyl. Acronyms for linear alkyl chains: C4: 1-butyl, C6: 1-hexyl, C8: 1-octyl, C12: 1-dodecyl, C14: 1-tetradecyl, C16: 1-hexadecyl, C18: 1-octadecyl. [b] Measured by cyclic voltammetry unless otherwise stated. [c] FET data unless otherwise stated. [d] Materials classified as either "amorph" (amorphous, no significant peaks observed in X-ray analysis), "semi" (semi-crystalline, typically only weak lamellar ordering) or "cryst" (crystalline, generally peaks from both polymer lamella and $\pi$-stacks). [e] Measured by photoelectron spectroscopy. [f] Estimated from the HOMO or the LUMO value and the optical band gap. [g] Charge carrier mobility measured by a zero-field technique such as SCLC. 
Table 2. Dithienyl-DPP Polymers

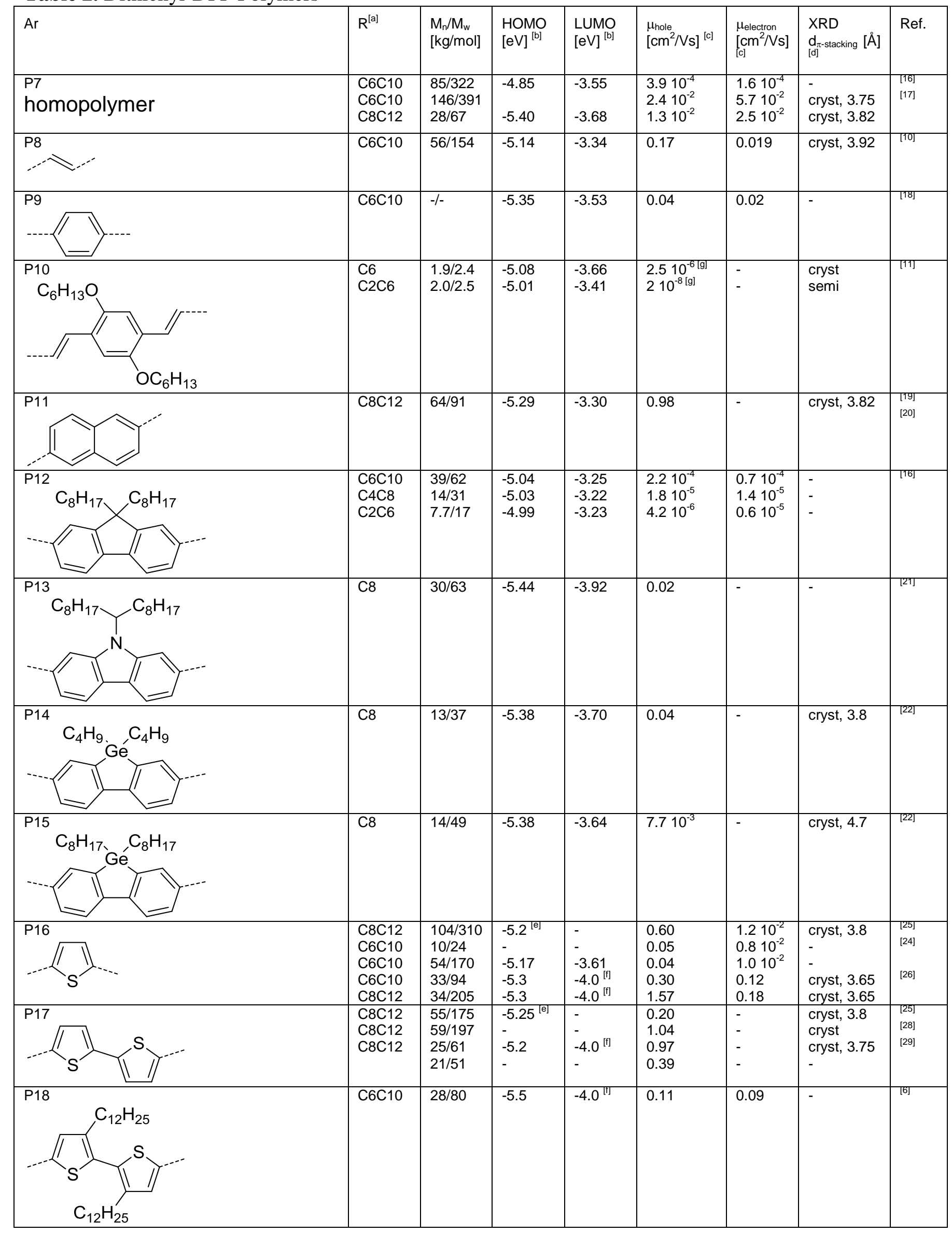




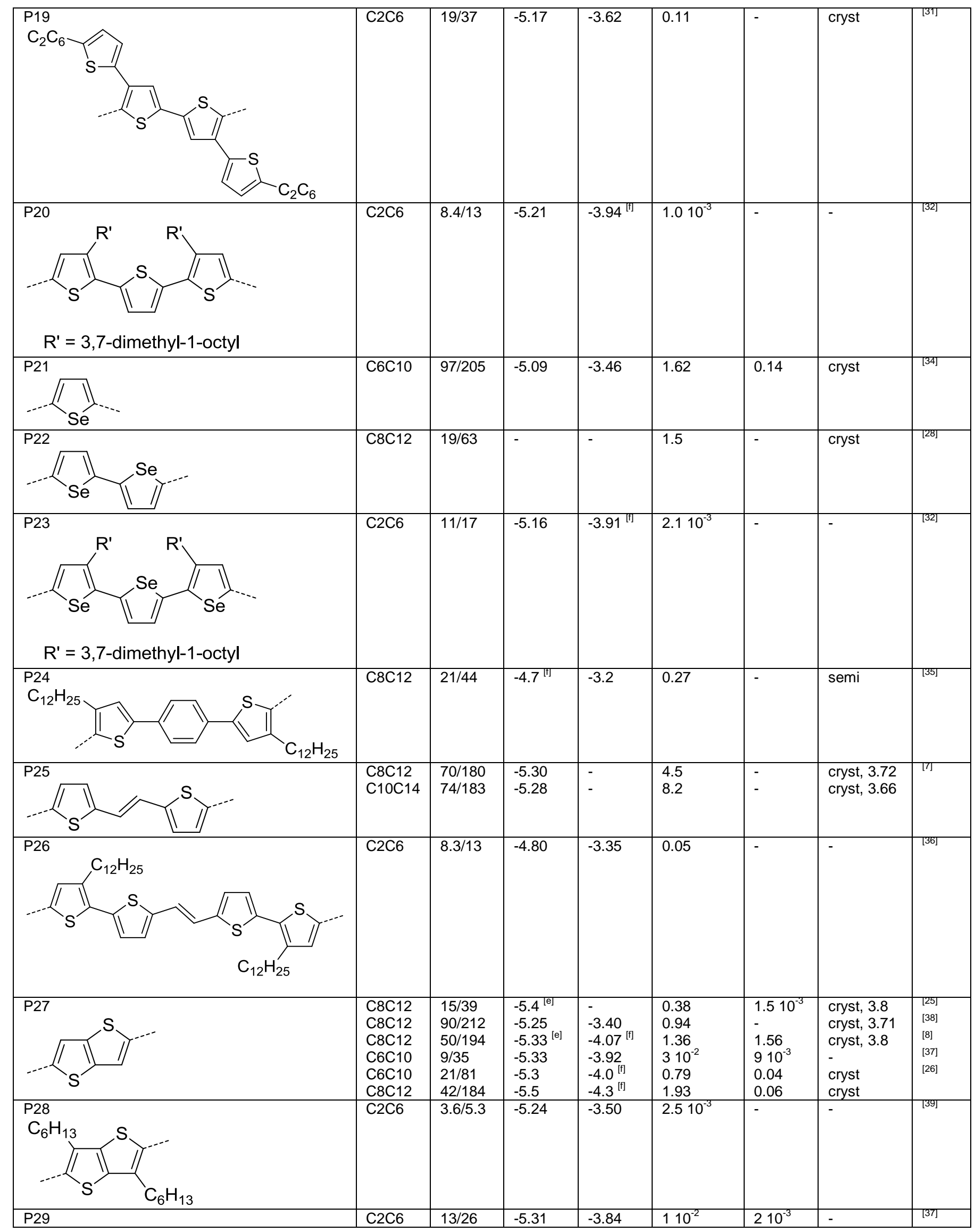




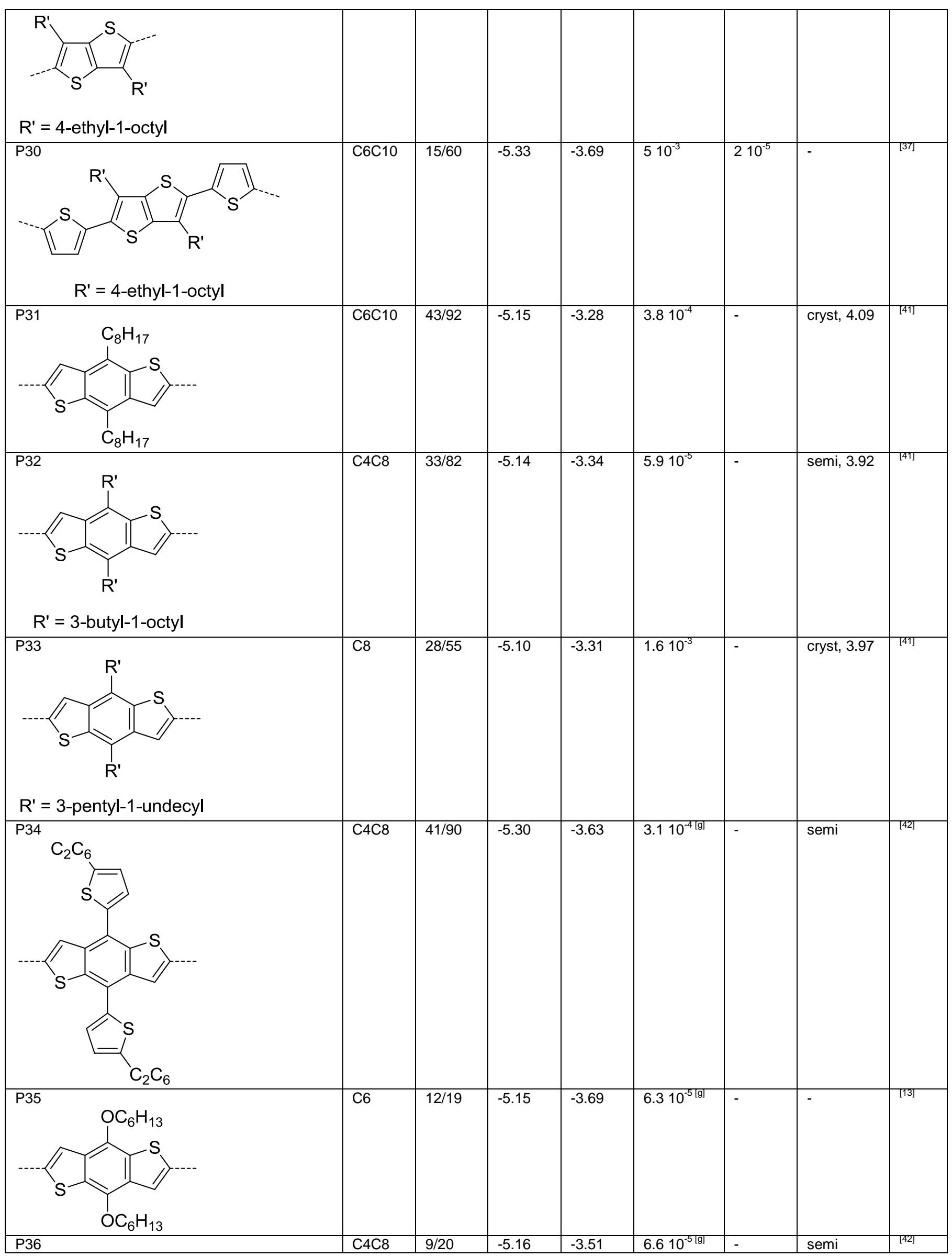




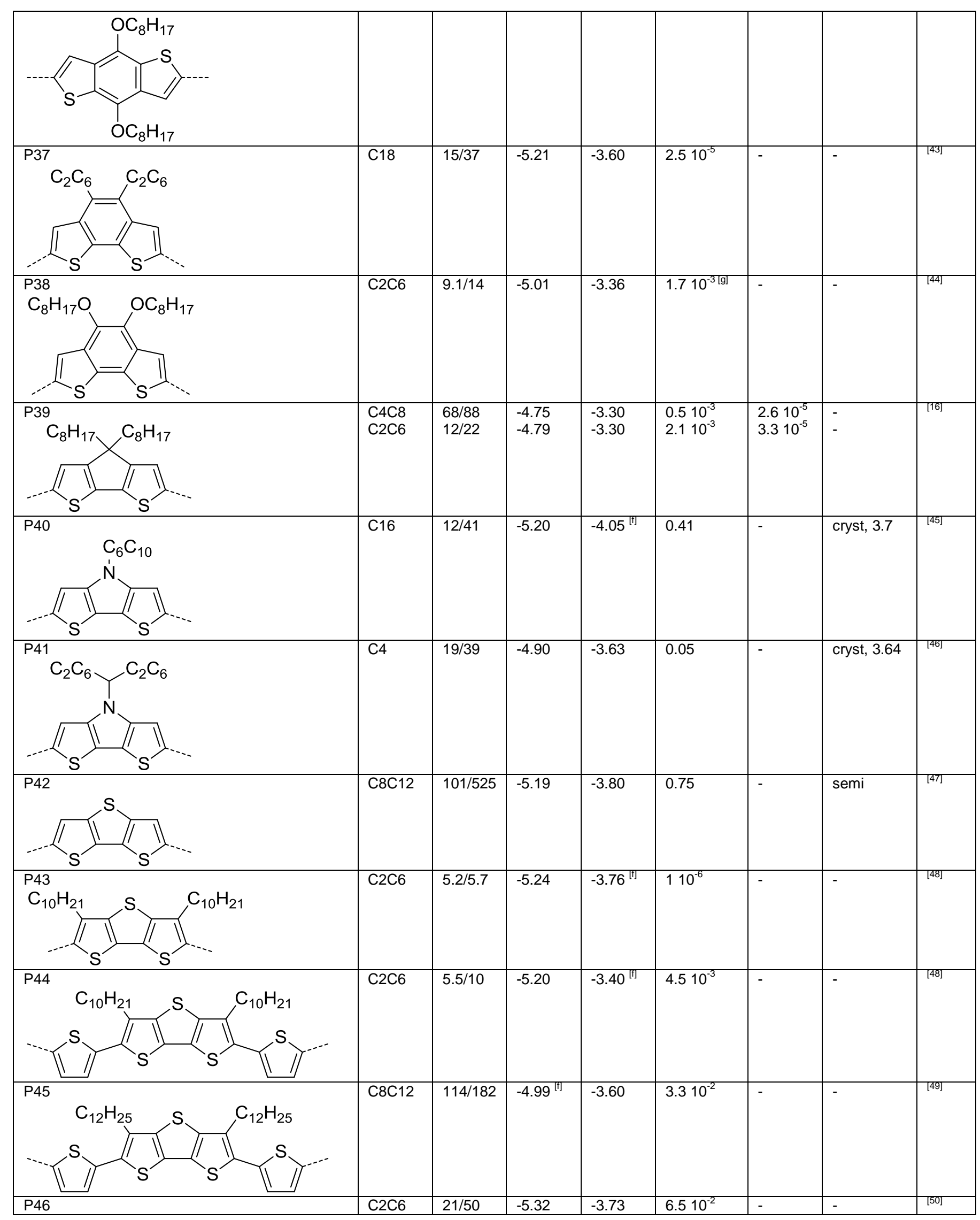




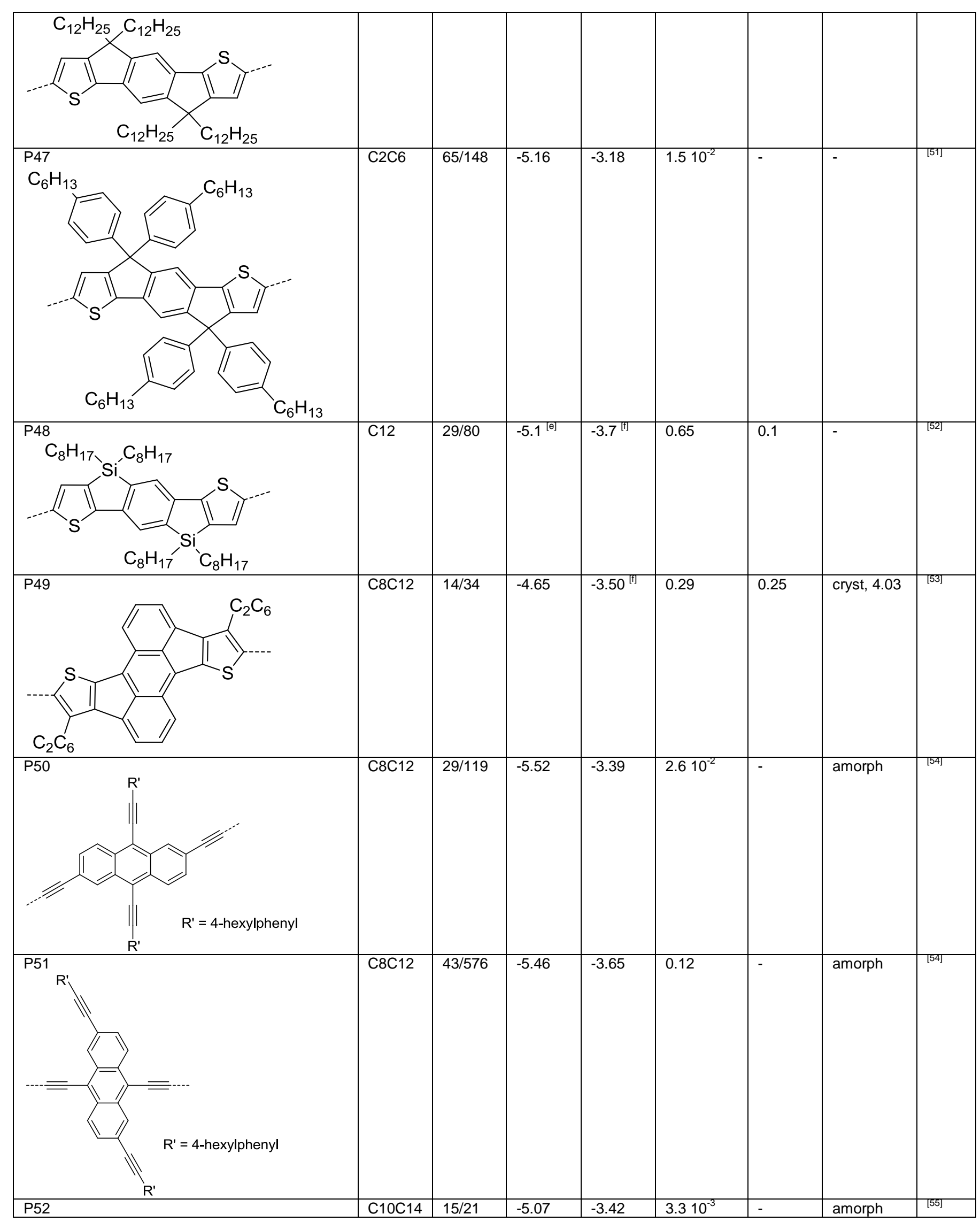




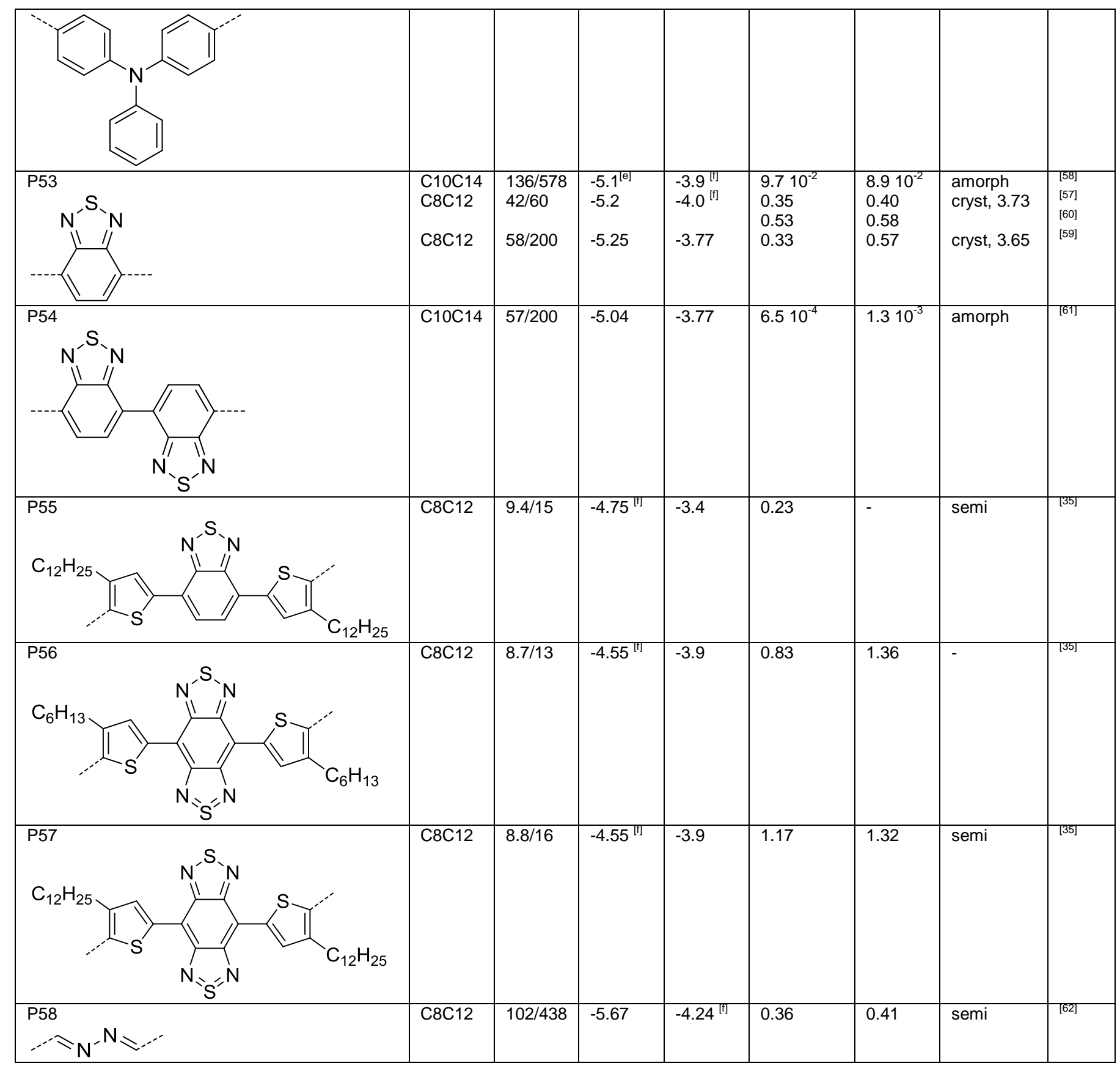

[a] The following acronyms are used for branched alkyl chains: C2C6: 2-ethyl-1-hexyl, C4C8: 2-butyl-1-octyl, C6C10: 2-hexyl-1-decyl, C8C12: 2-octyl-1-dodecyl, C10C14: 2decyl-1-tetradecyl. Acronyms for linear alkyl chains: C4: 1-butyl, C6: 1-hexyl, C8: 1-octyl, C12: 1-dodecyl, C14: 1-tetradecyl, C16: 1-hexadecyl, C18: 1-octadecyl. [b] Measured by cyclic voltammetry unless otherwise stated. [c] FET data unless otherwise stated. [d] Materials classified as either "amorph" (amorphous, no significant peaks observed in X-ray analysis), "semi" (semi-crystalline, typically only weak lamellar ordering) or "cryst" (crystalline, generally peaks from both polymer lamella and $\pi$-stacks). [e] Measured by photoelectron spectroscopy. [f] Estimated from the HOMO or the LUMO value and the optical band gap. [g] Charge carrier mobility measured by a zero-field technique such as SCLC. 
Table 3. Diaryl-DPP Polymers

\begin{tabular}{|c|c|c|c|c|c|c|c|c|c|}
\hline Ar1 & Ar2 & $\mathrm{R}^{[\mathrm{a}]}$ & $\begin{array}{l}\mathrm{M}_{\mathrm{n}} / \mathrm{M}_{\mathrm{w}} \\
{[\mathrm{kg} / \mathrm{mol}]}\end{array}$ & $\begin{array}{l}\mathrm{HOMO} \\
{[\mathrm{eV}]^{[\mathrm{b}]}}\end{array}$ & $\begin{array}{l}\text { LUMO } \\
{[\mathrm{eV}]^{[\mathrm{b}]}}\end{array}$ & $\begin{array}{l}\mu_{\text {hole }} \\
{\left[\mathrm{cm}^{2} / \mathrm{Vs}\right]}\end{array}$ & $\begin{array}{l}\mu_{\text {electron }} \\
{\left[\mathrm{cm}^{2} / \mathrm{Vs}\right]} \\
{[\mathrm{c}]}\end{array}$ & $\begin{array}{l}\text { XRD } \\
\mathrm{d}_{\pi \text {-stacking }} \\
{[\AA]^{[\mathrm{d}]}}\end{array}$ & Ref. \\
\hline P59 & & $\begin{array}{l}\text { C6C10 } \\
\text { C8C12 }\end{array}$ & $\begin{array}{l}17 / 94 \\
48 / 127\end{array}$ & $\begin{array}{l}-5.35 \\
-5.40\end{array}$ & $\begin{array}{l}-3.69 \\
-3.88\end{array}$ & $\begin{array}{l}310^{-3} \\
0.04\end{array}$ & $\begin{array}{l}710^{-3} \\
-\end{array}$ & - & $\begin{array}{l}{[64]} \\
{[63]}\end{array}$ \\
\hline P60 & & $\mathrm{C} 8 \mathrm{C} 12$ & $54 / 86$ & -5.34 & -3.85 & 0.11 & - & cryst, 4.18 & {$[63]$} \\
\hline P61 & & C8C12 & $21 / 26$ & -5.33 & -3.80 & 0.07 & - & cryst, 4.41 & {$[63]$} \\
\hline P62 & & $\mathrm{C} 6 \mathrm{C} 10$ & $13 / 36$ & -5.32 & -3.85 & $310^{-3}$ & $810^{-5}$ & & {$[64]$} \\
\hline P63 & & $\begin{array}{l}\mathrm{C} 6 \mathrm{C} 10 \\
\mathrm{C} 2 \mathrm{C6} \\
\mathrm{C} 12 \\
\mathrm{C} 14 \\
\mathrm{C} 16\end{array}$ & $\begin{array}{l}15 / 53 \\
56 / 88 \\
46 / 78 \\
58 / 92 \\
55 / 87\end{array}$ & $\begin{array}{l}-5.29 \\
-5.4^{[\mathrm{e}]} \\
-5.2^{[\mathrm{e}]} \\
-5.2^{[\mathrm{e}]} \\
-5.3^{[\mathrm{e}]}\end{array}$ & $\begin{array}{l}-3.84 \\
-3.8^{[f]} \\
-3.8^{[f]} \\
-3.8^{[f]} \\
-3.9^{[f]}\end{array}$ & $\begin{array}{ll} & 110^{-3} \\
2 & 10^{-3}[\mathrm{~g}] \\
4 & 10^{-4}[\mathrm{~g}] \\
7 & 10^{-4}[\mathrm{~g}] \\
2 & 10^{-3}[\mathrm{~g}]\end{array}$ & $\begin{array}{l}210^{-3} \\
- \\
- \\
- \\
-\end{array}$ & $\begin{array}{l}\text { - } \\
\text { cryst, } 3.7 \\
\text { cryst, } 3.6 \\
\text { cryst, } 3.6 \\
\text { cryst, } 3.6\end{array}$ & $\begin{array}{l}{[64]} \\
{[65]}\end{array}$ \\
\hline P64 & & $\mathrm{C} 8 \mathrm{C} 12$ & $131 / 296$ & -5.32 & -3.91 & 1.54 & - & cryst, 4.4 & {$[66]$} \\
\hline P65 & & $\mathrm{C} 8 \mathrm{C} 12$ & $13 / 29$ & $-5.22^{[e]}$ & $-3.81^{[t]}$ & 0.13 & - & semi & {$[6 / 1$} \\
\hline P66 & & $\mathrm{C} 8 \mathrm{C} 12$ & $205 / 450$ & -5.37 & -3.74 & 0.20 & 0.56 & semi & {$[68]$} \\
\hline P67 & & $\mathrm{C} 8 \mathrm{C} 12$ & $70 / 210$ & $-5.2^{[e]}$ & $-4.02^{[f]}$ & 0.1 & 0.1 & cryst, 3.8 & {$[69]$} \\
\hline P68 & & C8C12 & $100 / 250$ & $-5.1^{[e]}$ & $-3.92^{[t]}$ & 1.1 & 0.15 & cryst & {$[69]$} \\
\hline P69 & & C8C12 & $\begin{array}{l}30 / 69 \\
130 / 300\end{array}$ & -5.15 & -3.84 & $\begin{array}{l}0.46 \\
0.20\end{array}$ & $\begin{array}{l}0.84 \\
0.97\end{array}$ & cryst, 3.64 & $\lceil 59]$ \\
\hline P70 & hom & C8C12 & $16 / 78$ & $-5.04^{[e]}$ & $-3.76^{[t]}$ & 0.037 & 0.30 & semi & {$[10]$} \\
\hline P71 & & C8C12 & $14 / 75$ & $-5.06^{[e]}$ & $-3.68^{\text {[t] }}$ & 1.95 & 0.063 & semi & {$[70]$} \\
\hline
\end{tabular}

[a] The following acronyms are used for branched alkyl chains: C2C6: 2-ethyl-1-hexyl, C4C8: 2-butyl-1-octyl, C6C10: 2-hexyl-1-decyl, C8C12: 2-octyl-1-dodecyl, C10C14: 2decyl-1-tetradecyl. Acronyms for linear alkyl chains: C4: 1-butyl, C6: 1-hexyl, C8: 1-octyl, C12: 1-dodecyl, C14: 1-tetradecyl, C16: 1-hexadecyl, C18: 1-octadecyl. [b] Measured by cyclic voltammetry unless otherwise stated. [c] FET data unless otherwise stated. [d] 
Materials classified as either "amorph" (amorphous, no significant peaks observed in X-ray analysis), "semi" (semi-crystalline, typically only weak lamellar ordering) or "cryst" (crystalline, generally peaks from both polymer lamella and $\pi$-stacks). [e] Measured by photoelectron spectroscopy. [f] Estimated from the HOMO or the LUMO value and the optical band gap. [g] Charge carrier mobility measured by a zero-field technique such as SCLC. 
Christian B. Nielsen is a research associate in the Department of Chemistry at Imperial College London. He received his PhD in 2004 from the University of Copenhagen. His current research is focused on the design and synthesis of novel pi-conjugated materials aimed at the continued development of organic electronic applications such as field-effect transistors and solar cells.

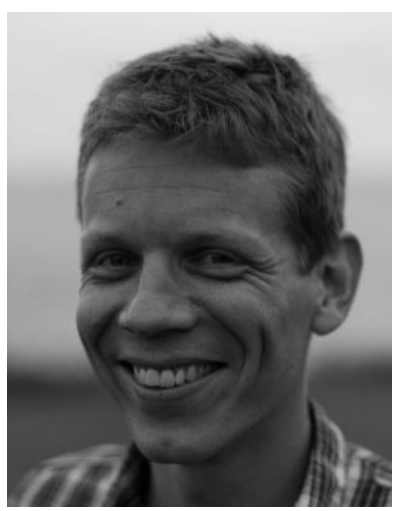

Mathieu Turbiez is heading the development of photoactive materials for solution processed OPV applications in the Research Centre of BASF in Basel. He received his PhD in 2003 from the University of Angers. After a post-doctoral position with Prof. René Janssen at the Technical University of Eindhoven in 2004, he joined Ciba Group Research in 2005 where he discovered the potential of DiketoPyrroloPyrrole (DPP) derivatives as high performance semi-conductors for OFET and OPV applications.

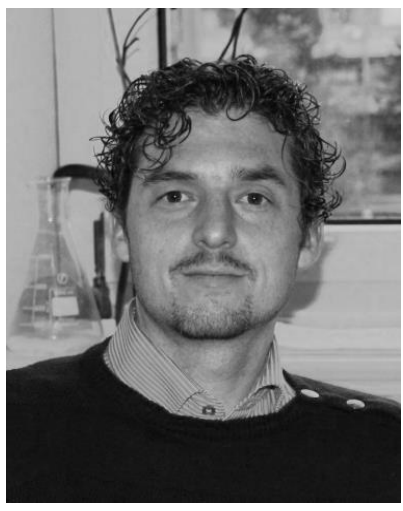

Iain McCulloch is Professor of Polymer Materials in the Department of Chemistry at Imperial College London, with research interests in organic semiconducting materials synthesis, characterization, and devices. He was previously the Organic Electronics Research Manager at Merck Chemicals. His achievements have been recognized with several awards including the Royal Society of Chemistry Creativity in Industry Prize. 


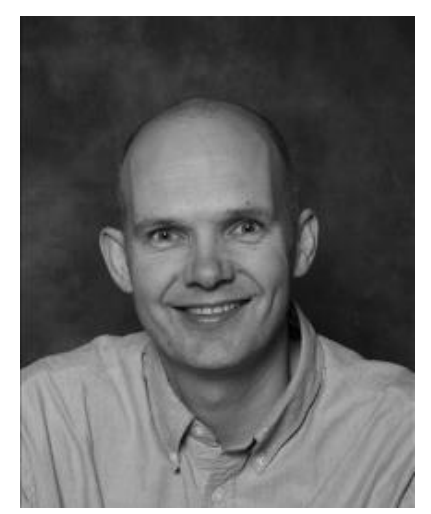


In this progress report, we critically review the most recent literature on diketopyrrolopyrrole-containing polymers developed for field-effect transistor applications and discuss in detail structure-property relations of importance for achieving high performance $n$ - and p-type transistor materials.

Keywords: conjugated polymers, donor-acceptor copolymers, field-effect transistors, semiconducting polymers, organic electronics

C. B. Nielsen, ${ }^{*}$ M. Turbiez, I. McCulloch

Recent Advances in the Development of Semiconducting DPP-Containing Polymers for Transistor Applications<smiles>[R]N1C(=O)C2=C(c3ccc(C4=CCC(C)CC4)cc3)N([R])C(=O)C2=C1c1ccc(C)cc1</smiles> 